\title{
Applying bayesian population assessment models to artisanal, multispecies fisheries in the Northern Mokran Sea, Iran
}

\author{
Abdul Rashid Jamnia', Ahmad Ali Keikha', Mahmoud Ahmadpour', \\ Abdoul Ahad Cissé2, Mohammad Rokouei ${ }^{3}$
}

I Department of Agricultural Economics, Faculty of Agriculture, University of Zabol, Zabol, Iran 2 LEEISA, UMSR University of French Guiana - CNRS - Ifremer, Cayenne, French Guiana 3 Department of Animal Sciences, Faculty of Agriculture, University of Zabol, Zabol, Iran

Corresponding author: Abdul Rashid Jamnia (a.r.jamnia@gmail.com)

Academic editor: M. Pinna | Received 22 March 2018 | Accepted 23 July 2018 | Published 13 August 2018

http://zoobank.org/7FBOAB56-276B-476E-BOEE-BDDF20BADFB6

Citation: Jamnia AR, Keikha AA, Ahmadpour M, Cissé AA, Rokouei M (2018) Applying bayesian population assessment models to artisanal, multispecies fisheries in the Northern Mokran Sea, Iran. Nature Conservation 28: 61-89. https://doi.org/10.3897/natureconservation.28.25212

\begin{abstract}
Small-scale fisheries substantially contribute to the reduction of poverty, local economies and food safety in many countries. However, limited and low-quality catches and effort data for small-scale fisheries complicate the stock assessment and management. Bayesian modelling has been advocated when assessing fisheries with limited data. Specifically, Bayesian models can incorporate information of the multiple sources, improve precision in the stock assessments and provide specific levels of uncertainty for estimating the relevant parameters. In this study, therefore, the state-space Bayesian generalised surplus production models will be used in order to estimate the stock status of fourteen Demersal fish species targeted by small-scale fisheries in Sistan and Baluchestan, Iran. The model was estimated using Markov chain Monte Carlo (MCMC) and Gibbs Sampling. Model parameter estimates were evaluated by the formal convergence and stationarity diagnostic tests, indicating convergence and accuracy. They were also aligned with existing parameter estimates for fourteen species of the other locations. This suggests model reliability and demonstrates the utility of Bayesian models. According to estimated fisheries' management reference points, all assessed fish stocks appear to be overfished. Overfishing considered, the current fisheries management strategies for the small-scale fisheries may need some adjustments to warrant the long-term viability of the fisheries.
\end{abstract}

\section{Keywords}

Small-scale Demersal fisheries, Bayesian modelling, Generalised surplus production

Copyright Abdul Rashid Jamnia et al. This is an open access article distributed under the terms of the Creative Commons Attribution License (CC BY 4.0), which permits unrestricted use, distribution, and reproduction in any medium, provided the original author and source are credited. 


\section{Introduction}

Human dependency on maritime and coastal resources is increasing (Berkes 2001). It is often indicated that a small-scale fishery is a mainly pro-poor activity because it is an economic sector that is labour-intensive and comparatively easy to enter; and provides the fields of livings to a large number of uneducated people, including women through their participation in fish processing activities. These small-scale artisanal fisheries substantially contribute to the poverty alleviation, local economies and food security in many countries. They engage 50 of the world's 51 million fishermen, all of whom are actually from developing countries (Neiland and Béné 2013). In the tropical and subtropical coastal domains, small-scale fisheries account for the majority of catches (Berkes 2001; Salas et al. 2007) and are considered as the more sustainable method of fishing (Matthew 2003; Pauly 2006).

Increased over-exploitation of fishery and habitat destruction threaten the coastal and maritime resources. Small-scale fisheries often have limited and low-quality catch and effort data that complicates stock assessment and management. Globally, for example, only $10 \%$ to $50 \%$ of fish stocks in more developed countries and 5\% to $20 \%$ of fish stocks in less-developed countries have been scientifically assessed due to limited data (Chen et al. 2003; Costello et al. 2012; Jiao et al. 2011). To enhance the sustainability of small-scale fisheries, therefore, suitable and reliable stock assessments are required (Berkes 2001; Hilborn and Walters 1992; Jiao et al. 2011; Xiao 1998).

Based on the various works (Valinassab et al. 2010; Valinassab et al. 2003; Valinassab et al. 2006; Valinassab et al. 2005) and the reports from the Offshore Fisheries Research Centre of Chabahar (OFRC) and the Provincial Fisheries Department of Sistan and Balochestan (PFDSB), the following fourteen demersal fish species are the most important economically: Fourfinger threadfin (Elutheronema tetradactylum), Smalltooth emperors (Lethrinus microdon), John's snapper (Lutjanus johni), Malabar blood snapper (Lutjanus malabaricus), Tigertooth croaker (Otolithes ruber), Silver pomfret (Pampus argenteus), Black pomfret (Parastromateus niger), Bartail flathead (Platycephalus indicus), Javelin grunter (Pomadasys kaakan), Blackspotted croaker (Protonibea diacanthus), Greater lizardfish (Saurida tumbil), Talang queen fish (Scomberoides commersonnianus), Goldlined seabream (Rhabdosargus sarba) and Indian pompano (Trachinotus mookalee). In addition, the above-mentioned fish species have been recorded as the kinds that their abundance is in reduction and local extinctions have been recorded by relevant organisations such as Iran Fisheries Organization (IFO) and PFDSB. However, no wide fishery stock assessments have been undertaken. Therefore, they are selected as targeted species in current study.

Mostly, due to insufficient information about the time series of biological and management reference points of fish stocks, the scientific precise stock assessments have not been undertaken for the majority of fish species in Iran, especially in the southern coastal areas (the current study area). Therefore, due to the lack of information toward fisheries management reference points, most fisheries planning has not had any special effects on the sustainability of fish stocks reserves. 
So far, there has been a lot of scientific motivation for assessing fish stocks in Iran, but it has not been implemented for two reasons; one the lack of sufficient information used in scientific stock assessment methods and second the complexity and timeconsuming of stock assessment methods in the limited-data situations.

Bayesian modelling has been advocated to assess fisheries with limited data. Specifically, Bayesian models can incorporate information of the multiple sources such as academic literature, empirical research, biological theory and specialist judgement. This characteristic of the Bayesian models improves precision in the stock assessments and provides the specific levels of uncertainty for estimating the parameters (Kuparinen et al. 2012; McAllister and Kirkwood 1998; Punt et al. 2011).

Therefore, in the current study, because of the limited data, the state-space Bayesian generalised surplus production models used to estimate the stocks status of the fourteen demersal fish species targeted by small-scale fisheries in Sistan and Baluchestan (A coastal province south-east of Iran). This could provide scientific knowledge for the fisheries management and contribute to the researchers applying and improving the results of the current study in order to achieve the global environmental sustainability and marine ecology.

Hence, in the current study, based on the above-mentioned stock assessment Bayesian approach, the management reference points provided for the fourteen fish species, including biomass, harvest rate and stock status, the implication of these for the sustainable management of the small-scale fisheries was discussed. Moreover, the estimates of biological parameters were compared to the previous findings of the fourteen species.

\section{Materials, methods and data selection}

\section{Study area and data source}

The fisheries examined in this study are located in the Sistan and Baluchestan Province (SBP) situated at the northern end of Mokran Sea (Gulf of Oman) in Iran (Pakzad et al. 2014). There are ten ports along a $270 \mathrm{~km}$ (167.77 miles) stretch of coastline from Govater Bay in the East to Kereti Bay in the West, spanning a longitude $59^{\circ} 13^{\prime} \mathrm{E}$ to $61^{\circ} 13^{\prime} \mathrm{E}$ (Figure 1).

Based on the local reportage of PFDSB and IFO, the fishery is an important source of income, cultural heritage and recreation in the area. In addition, it forms the largest employment with over 24,500 locals involved in fishing industries permanently or seasonally. The fishing system of SBP consists of inshore fleets, with $60 \%$ (1430) of vessels registered as weighing at least three gross tonnes, as most of which are primarily made of fibreglass. The fishing activities are mainly seasonal and fishermen change their fishing gear (gill nets, hand-lines/hook-and-lines and traps) and strategies based on water levels, habitats, migration patterns and species targeted. However, the majority of vessels that fish annually use gill nets. The total catches of 


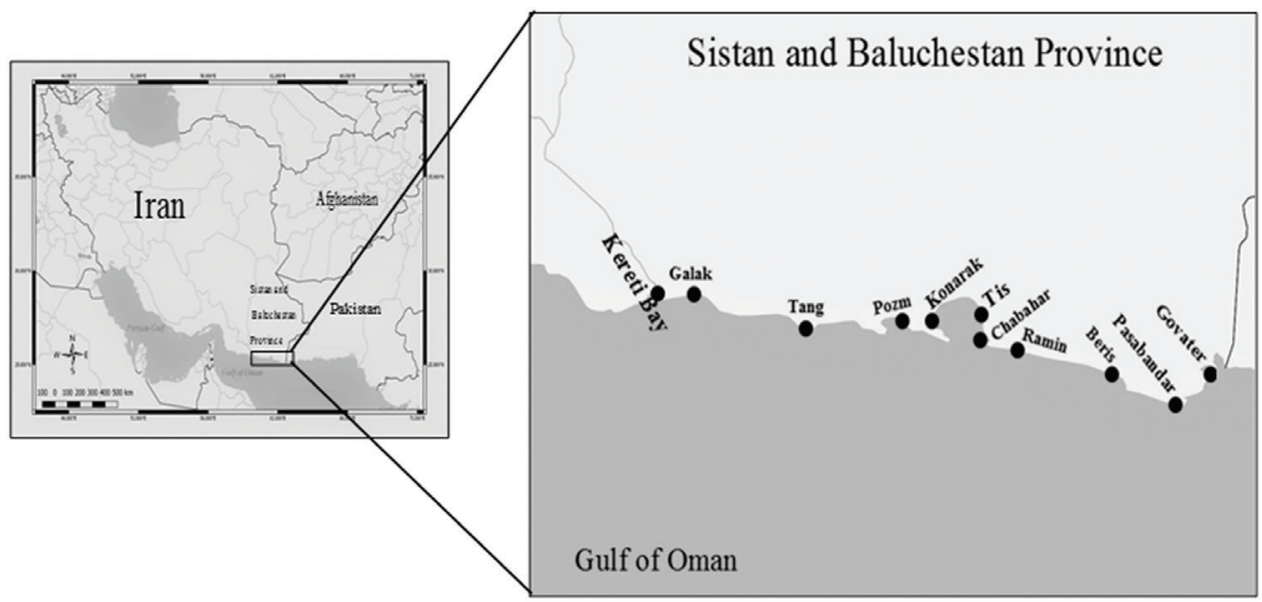

Figure I. Study area and the locations of fishing landing ports related to small scale fishing vessels.

the fourteen species examined in this study from 21 March 2015 to 18 March 2016 were 35,937 metric tonnes. This catch comprises $49 \%$ of the demersal fish catch; $31 \%$ of all fish species caught and 187 million US\$ of economic value which represents an important resource for the fishery.

Nine years (21 March 2006 to 18 March 2015) of fisheries-dependent commercial landings and effort data for the fourteen demersal fish species listed earlier were acquired from Iran's National Fishery Data Collection and Reporting System Unit and also reports from the Provincial Fisheries Department. In addition, the used time series of catch and standardised CPUE values as relative abundance indices are considerable as the supplementary data. The nominal CPUE indices that derived from commercial fisheries' logbooks are affected by some variables such as spatiotemporal and environmental factors. The considered standardised CPUE indices are reliable abundance indices which allow the implementation of the conservation and management measures and have been obtained by the most common and competent statistical approach in the domain of fisheries' researches, such as generalised additive models (GAMs), that are used for standardising catch and effort data.

\section{Modelling methods}

Biomass dynamic models are popularly used for stock assessment when only catch and effort time series data are accessible (Hilborn and Walters 1992; Kinas 1996; Laloë 1995; Mäntyniemi et al. 2015; Quinn and Deriso 1999). These models equate current biomass as previous biomass plus surplus production (growth, recruitment and natural mortality) minus harvest removals (Hilborn and Walters 1992; McAllister and Kirkwood 1998; Schaefer 1957). 
The biomass dynamics model of the equation discrete time form is as follows (Hilborn and Walters 1992):

$$
B_{t}=B_{t-1}+h\left(B_{t-1}\right)-C_{t-1}
$$

In Equation 1, $B_{t-1}, C_{t-}$ and $h\left(B_{t-1}\right)$ denote biomass and catch for year $t-1$ and the surplus production function, respectively.

\section{Bayesian state-space surplus production model}

Bayesian state-space models consist of three levels (Berliner 1996; De Valpine and Hastings 2002; Haddon 2010; Parent and Rivot 2012) as follows:

(I) a process equation which depicts the time dynamics of a stochastic process as a function of time-invariant hyper-parameters. (II) an observation equation based on population-specific inspection data that are a function of the unobserved state process (Buckland et al. 2004). (III) the prior distributions level that comprises an explanation of the prior probability distribution of the parameters and condition at the first time moment (Rankin and Lemos 2015). These three levels are specified in the following section in the background of a surplus production model.

\section{Process equation}

With regards to the Equation 1, the process equation describes the surplus production function in a generalised surplus production model (GSPM) (Fletcher 1978; Pella and Tomlinson 1969) as follows:

$$
h\left(B_{t-1}\right)=r B_{t-1}\left(1-\left(B_{t-1} / K\right)^{z}\right), r>0, K>0, z>0
$$

where $r$ is the intrinsic population growth rate; $K$ is the carrying capacity of the population and $z$ is the shape parameter of the production model that determines at which $\mathrm{B} / \mathrm{K}$ ratio maximum surplus production was attained and commonly noted as equivalent biomass and at which the maximum sustainable yield (MSY) was attained $\left(B_{M S Y}\right)$. If the shape parameter was less than unity $(0<z<1)$, then surplus production would increase (to the peak point) when the biomass was below K/2 (a left-skewed production curve). If the shape parameter was greater than unity $(z>1)$, then biomass production would increase (to the peak point) when the biomass was more than $\mathrm{K} / 2$ (a right-skewed production curve). If the shape parameter was identical to unity $(z=1)$, the production model would reduce to the Schafer form, attaining MSY when biomass was equal to $\mathrm{K} / 2$. If $z$ approached zero $(z \rightarrow 0)$, the production model would reduce to the Fox model that results into maximum surplus production at $\sim 0.37 \mathrm{~K}$. 
Replacing Equation 2 in Equation 1 and multiplying the right hand side of the resultant equation with $u_{t}$ yields the stochastic form of the biomass dynamic model with generalised surplus production (GSP) (Parent and Rivot 2012):

$$
B_{t}=\left(B_{t-1}+r_{t} B_{t-1}\left(1-\left(B_{t-1} / K\right)^{\mathrm{z}}\right)-C_{t-1}\right) u_{t}
$$

Where $u_{t}$ is process noise - supposed to be independent and log-normally distributed; specifically $u_{t}=e^{\varepsilon_{t}}$ where $\varepsilon_{t} \sim N\left[0, \sigma^{2}\right]$, i.e. $\varepsilon_{t}$ is i.i.d. normal with mean zero and variance $\sigma^{2}$.

Equation 3 was re-parameterised using relative biomass $\left(P=B_{t} / K\right)$ to diminish parameter confounding such as that between biomass and $K$ that could result in related priors (Meyer and Millar 1999) as follows. Thus, the final stochastic form of the process equation is given by Equation 4:

$$
P_{t}=\left(P_{t-1}+\mathrm{r}_{t} P_{t-1}\left(1-\left(P_{t-1}\right)^{z}\right)-C_{t-1} / K\right) u_{t}
$$

\section{Observation equation}

According to regular assumptions, CPUE values are relative abundance indices proportional to the biomass. The observation equation relates the unobserved states $B_{t}$ to the relative abundance indices $I_{t}$ (Harley et al. 2001; Bishop 2006; Ye and Dennis 2009; Yu et al. 2013). Thus, the observation equation with log-normally distributed errors to attain the stochastic observation equation (Rankin and Lemos 2015) can be written as Equation 5:

$$
I_{t}=q K P_{t} v_{t}
$$

where $I_{t}$ is the relative biomass index; $q$ is the "catchability" coefficient that indicates the effectiveness of each unit of fishing effort and $v_{t}$ is the observation error entered as an independent and log-normally distributed random variable. Specifically, $v_{t}=\mathrm{e}^{\eta_{t}}$ where $\eta_{t} \sim N\left[0, \tau^{2}\right]$, i.e. is $\eta_{t}$ i.i.d. normal with mean zero and variance $\tau^{2}$.

\section{Parameter prior distribution layer}

An advantage of the Bayesian models is its ability to use the prior distributions based upon the existing knowledge to set plausible values for model parameters (Gelman et al. 2014). The generalised surplus production model (GSPM) parameters include the carrying capacity $K$, the intrinsic growth rate $r$, the shape parameter $z$, the catchability coefficient $q$, the process and observation noise variances $\sigma^{2}$ and $\tau^{2}$ and the proportion of initial biomass to carrying capacity $P$. 
The reason for choosing the priors was based on the following rationale. First, based on the expert consultations of IFO and PFDSB and the available information from Valinassab et al. 2010; Valinassab et al. 2003; Valinassab et al. 2006 and Valinassab et al. 2005, an objective and informative uniform prior for carrying capacity, K, was specified with a lower frontier of the supreme reported landings and an upper frontier equal to fifty times the lower boundary as values below or above this are unlikely. According to Cheung and Sumaila (2015), FishBase (http://www.fishbase.org), and expert consultations of OFRC and PFDSB, an objective and informative lognormal distribution priors were adopted for the intrinsic growth rate $r$. Based on the method presented in Parent and Rivot (2012) and Montenegro and Branco (2016), a rather diffuse prior (inverse-Gamma $(0.001,0.001)$ ) provided for the catchability coefficient $q$, and also, according to King et al. 2009, a non-informative gamma distribution prior with parameters $(2,2)$, selected for the shape parameter $z$. In addition, the considerable prior in Table 1 for the initial relative biomass $\mathrm{P}[1]$, was based on Valinassab et al. 2010; Valinassab et al. 2003; Valinassab et al. 2006; and Valinassab et al. 2005 and reported landings from IFO and PFDSB were specified as an objective and informative lognormal distribution. In addition, some required procedure of the used prior distributions functions were presented in (Appendix 1) for parameters.

Based on Kéry and Schaub (2011) and Gelman and Meng (2004), Jiao et al. (2008), Meyer and Millar (1999), Millar (2002), and Seaman et al. (2012), the Bayesian population assessments, particularly estimates of state-space models, especially the process and observation noise variances $\sigma^{2}$ and $\tau^{2}$, are more sensitive to the prior specifications than the other parameters. Therefore, in order to ensure that the results of the study were not misleading due to the inappropriate selection of prior distribution of the $\sigma^{2}$ and $\tau^{2}$, the various prior distribution combinations were opted and examined as follows. In the first stage, the same Inverse-Gamma with parameters $(0.001,0.001)$ was designated for the above-mentioned two variance parameters. With those priors, the Markov Chain Monte Carlo (MCMC) algorithm convergence and stationarity were not verified based on the formal diagnosis tests. Therefore, a uniform prior distribution $\mathrm{U}(0,100)$ was used for the $\sigma^{2}$ and $\tau^{2}$, equivalently. Again, as in the previous stage, the (MCMC) algorithm convergence and stationarity were not confirmed based on formal diagnosis tests. Finally, after a trial and error process on changing the shape and scale parameters of Inverse-Gamma distribution, the best prior distribution as two InverseGamma with parameters $(15,0.1)$ and $(10,0.1)$ was selected for the process and observation noise variances $\sigma^{2}$ and $\tau^{2}$, respectively. Furthermore, to the aforementioned prior distributions details, a summary of the prior distribution values for the $\mathrm{P}[1], \mathrm{K}$ and $\mathrm{r}$ is presented in Table 1.

\section{Fisheries management reference points}

The major fisheries reference points for the GSPM (Chaloupka and Balazs 2007; Punt and Szuwalski 2012; Zhu et al. 2014) examined in this study are as follows: 
Table I. Summary of the Prior distribution functions used for some parameters of all bayesian state-space GSPM Fourteen specified high-commercial demersal fish species.

\begin{tabular}{|c|c|c|c|}
\hline \multirow{2}{*}{ Species } & \multicolumn{3}{|c|}{ Parameter } \\
\hline & Intrinsic growth rate, $r$ & Carrying capacity, $\mathrm{K}$ & Initial condition, $\mathrm{P}[1]$ \\
\hline $\begin{array}{l}\text { Elutheronema } \\
\text { tetradactylum }\end{array}$ & $\mathrm{r} \sim \operatorname{lognormal}(-1.1139,4.4814)$ & $\mathrm{K}-$ uniform $(604,30200)$ & $\begin{array}{c}\mathrm{pi} \sim \operatorname{uniform}(0.01,0.135) \\
\mathrm{pm}=\log (\mathrm{pi}) \\
\mathrm{P}[1] \sim \operatorname{lognormal}\left(\mathrm{pm}, 1 / \sigma^{2}\right)\end{array}$ \\
\hline $\begin{array}{l}\text { Lethrinus } \\
\text { microdon }\end{array}$ & $\mathrm{r} \sim \operatorname{lognormal}(-0.2326,4.4814)$ & $\mathrm{K}$ - uniform $(1089,54450)$ & $\begin{array}{c}\mathrm{pi}-\operatorname{uniform}(0.0132,0.125) \\
\mathrm{pm}=\log (\mathrm{pi}) \\
\mathrm{P}[1]-\operatorname{lognormal}\left(\mathrm{pm}, 1 / \sigma^{2}\right)\end{array}$ \\
\hline Lutjanus johni & $\mathrm{r} \sim \operatorname{lognormal}(-1.4741,4.4814))$ & $\mathrm{K}$ - uniform $(1180,59000)$ & $\begin{array}{c}\mathrm{pi}-\operatorname{uniform}(0.019,0.116) \\
\mathrm{pm}=\log (\mathrm{pi}) \\
\mathrm{P}[1]-\operatorname{lognormal}\left(\mathrm{pm}, 1 / \sigma^{2}\right)\end{array}$ \\
\hline $\begin{array}{l}\text { Lutjanus } \\
\text { malabaricus }\end{array}$ & $\mathrm{r} \sim$ lognormal $(-1.2447,4.4814)$ & $\mathrm{K} \sim$ uniform $(704,35200)$ & $\begin{array}{c}\mathrm{pi} \sim \operatorname{uniform}(0.012,0.14) \\
\mathrm{pm}=\log (\mathrm{pi}) \\
\mathrm{P}[1] \sim \operatorname{lognormal}\left(\mathrm{pm}, 1 / \sigma^{2}\right)\end{array}$ \\
\hline Otolithes ruber & $\mathrm{r} \sim \operatorname{lognormal}(-1.9888,4.4814)$ & $\mathrm{K}$ - uniform $(4187,209350)$ & $\begin{array}{c}\mathrm{pi} \sim \operatorname{uniform}(0.01,0.135) \\
\mathrm{pm}=\log (\mathrm{pi}) \\
\mathrm{P}[1] \sim \operatorname{lognormal}\left(\mathrm{pm}, 1 / \sigma^{2}\right)\end{array}$ \\
\hline Pampus argenteus & $\mathrm{r} \sim \operatorname{lognormal}(-0.5547,4.4814)$ & $\mathrm{K}-$ uniform $(569,28450)$ & $\begin{array}{c}\mathrm{pi}-\operatorname{uniform}(0.014,0.132) \\
\mathrm{pm}=\log (\mathrm{pi}) \\
\mathrm{P}[1] \sim \operatorname{lognormal}\left(\mathrm{pm}, 1 / \sigma^{2}\right)\end{array}$ \\
\hline $\begin{array}{l}\text { Parastromateus } \\
\text { niger }\end{array}$ & $\mathrm{r} \sim \operatorname{lognormal}(-1.8574,4.4814)$ & $\mathrm{K}$ - uniform $(6456,322800)$ & $\begin{array}{c}\text { pi } \sim \text { uniform }(0.01,0.121) \\
\text { pm }=\log (\mathrm{pi}) \\
\mathrm{P}[1] \sim \operatorname{lognormal}\left(\mathrm{pm}, 1 / \sigma^{2}\right)\end{array}$ \\
\hline $\begin{array}{l}\text { Platycephalus } \\
\text { indicus }\end{array}$ & $\mathrm{r} \sim \operatorname{lognormal}(-2.0425,4.4814)$ & $\mathrm{K}$ - uniform $(1076,53800)$ & $\begin{array}{c}\mathrm{pi} \sim \operatorname{uniform}(0.0126,0.113) \\
\mathrm{pm}=\log (\mathrm{pi}) \\
\mathrm{P}[1] \sim \operatorname{lognormal}\left(\mathrm{pm}, 1 / \sigma^{2}\right)\end{array}$ \\
\hline $\begin{array}{l}\text { Pomadasys } \\
\text { kaakan }\end{array}$ & $r \sim \operatorname{lognormal}(0.0615,4.4814)$ & $\mathrm{K}$ - uniform $(2992,149600)$ & $\begin{array}{c}\mathrm{pi} \sim \operatorname{uniform}(0.01,0.114) \\
\mathrm{pm}=\log (\mathrm{pi}) \\
\mathrm{P}[1] \sim \operatorname{lognormal}\left(\mathrm{pm}, 1 / \sigma^{2}\right)\end{array}$ \\
\hline $\begin{array}{l}\text { Protonibea } \\
\text { diacanthus }\end{array}$ & $\mathrm{r} \sim \operatorname{lognormal}(-1.0531,4.4814)$ & $\mathrm{K}$ - uniform $(4429,221450)$ & $\begin{array}{c}\mathrm{pi}-\text { uniform }(0.0171,0.1587) \\
\mathrm{pm}=\log (\mathrm{pi}) \\
\mathrm{P}[1] \sim \operatorname{lognormal}\left(\mathrm{pm}, 1 / \sigma^{2}\right)\end{array}$ \\
\hline Saurida tumbil & $\mathrm{r} \sim$ lognormal $(-0.9886,4.4814)$ & $\mathrm{K}-\operatorname{uniform}(2170,108500)$ & $\begin{array}{c}\mathrm{pi} \sim \operatorname{uniform}(0.0154,0.1286) \\
\mathrm{pm}=\log (\mathrm{pi}) \\
\mathrm{P}[1]-\operatorname{lognormal}\left(\mathrm{pm}, 1 / \sigma^{2}\right)\end{array}$ \\
\hline $\begin{array}{l}\text { Scomberoides } \\
\text { commersonnianus }\end{array}$ & $\mathrm{r} \sim \operatorname{lognormal}(-1.5099,4.4814)$ & $\mathrm{K}$ - uniform $(11001,55005)$ & $\begin{array}{c}\mathrm{pi} \sim \operatorname{uniform}(0.0194,0.105) \\
\mathrm{pm}=\log (\mathrm{pi}) \\
\mathrm{P}[1] \sim \operatorname{lognormal}\left(\mathrm{pm}, 1 / \sigma^{2}\right)\end{array}$ \\
\hline $\begin{array}{l}\text { Rhabdosargus } \\
\text { sarba }\end{array}$ & $\mathrm{r} \sim \operatorname{lognormal}(-1.0634,4.4814)$ & $\mathrm{K}-\operatorname{uniform}(1746,87300)$ & $\begin{array}{c}\mathrm{pi}-\text { uniform }(0.0164,0.1613) \\
\mathrm{pm}=\log (\mathrm{pi}) \\
\mathrm{P}[1] \sim \operatorname{lognormal}\left(\mathrm{pm}, 1 / \sigma^{2}\right)\end{array}$ \\
\hline $\begin{array}{l}\text { Trachinotus } \\
\text { mookalee }\end{array}$ & $\mathrm{r} \sim \operatorname{lognormal}(-1.7514,4.4814)$ & $\mathrm{K}$ - uniform $(712,35600)$ & $\begin{array}{c}\mathrm{pi} \sim \operatorname{uniform}(0.0163,0.12) \\
\mathrm{pm}=\log (\mathrm{pi}) \\
\mathrm{P}[1] \sim \operatorname{lognormal}\left(\mathrm{pm}, 1 / \sigma^{2}\right)\end{array}$ \\
\hline
\end{tabular}

The stock biomass at which the maximum sustainable yield (MSY) was attained $\left(B_{M S Y}\right)$ is given as Equation 6:

$$
B_{M S Y}=K(z+1)^{(-1 / z)}
$$


whilst, $F_{M S Y}$ is the fishing mortality corresponding to MSY and is described as Equation 7:

$$
F_{M S Y}=K(z+1)^{(-1 / z)}
$$

The related value of MSY is calculated as Equation 8:

$$
M S Y=B_{M S Y} F_{M S Y}=K(z+1)^{(-1 / z)} \cdot r(z+1)^{(-1 / z)}=K r(z+1)^{(-2 / z)}
$$

Finally, the relative fishing mortality rate $F_{S}$ and relative biomass $B_{S}$ are assessed by $F_{S}=F_{t} / F_{M S Y}$ and $B_{S}=B_{t} / B_{M S Y}$, respectively.

\section{Model fitting}

The Bayesian state-space combines the joint prior distributions of all parameters and unobservable conditions with the likelihood functions of the observations (Brodziak and Ishimura 2011; Meyer and Millar 1999; Punt and Hilborn 1997). Due to the conditional independence between the model parameters and unobserved conditions, the joint posterior distribution of the unobservable data, $\left(p\left(\mathrm{~K}, \mathrm{r}, \mathrm{q}, \mathrm{z}, \sigma^{2}, \tau^{2}, P_{1}, \ldots, P_{N}\right.\right.$ $\left(I_{1}, \ldots, I_{N}\right)$ ), is proportional to the joint posterior distribution of all un-observables and observables (Meyer and Millar 1999; Montenegro and Branco 2016; Rankin and Lemos 2015) formulated as Equation 9:

$$
\begin{aligned}
& p\left(\mathrm{~K}, \mathrm{r}, \mathrm{q}, \mathrm{z}, \sigma^{2}, \tau^{2}, P_{1}, \ldots, P_{n}, I_{1}, \ldots, I_{n}\right)=[K] \times[r] \times[q] \times[z] \times\left[\sigma^{2}\right] \times\left[\tau^{2}\right] \times\left[P_{1} \mid \sigma^{2}\right] \\
& \times \prod_{t=2}^{N} p\left(P_{t} \mid P_{t-1}, K, r, z, \sigma^{2}\right) \times \prod_{t=1}^{N} p\left(I_{t} \mid P_{t}, K, q, \tau^{2}\right)
\end{aligned}
$$

with square brackets indicating densities and $\mathrm{N}$ referring to the number of samples. Supplementary information on the above-mentioned general factorisation of Bayesian model (Eq. 9) is available in Wikle et al. 1998 and Clark and Gelfand 2006.

The Markov chain Monte Carlo (MCMC) algorithm using Gibbs sampling was used to explore the joint posterior distributions of the parameters and un-observable states. OpenBugs software (v3.2.3) (Thomas et al. 2006) was used for simulations and was run within $\mathrm{R}$ using the R2OpenBugs package (Sturtz et al. 2010). Three chains of 100,000 iterations used to estimate parameters for the model of each fish species. The first 50,000 iterations of each chain were discarded to remove any dependence on initial parameter values; as well, random initial values were generated for each chain. The resulting 50,000 samples were thinned at a rate of 1:5 to remove autocorrelation. This results in a sample size of 10,000 per chain to assess 
the summary statistics of parameter posterior distributions. Model convergence was assessed with the convergence diagnostics of Geweke (Geweke 1991), GelmanRubin's potential scale reduction measure (Gilks et al. 1996) and Heidelberger and Welch stationarity (Heidelberger and Welch 1983), calculated using the R-package CODA (Plummer et al. 2006).

\section{Results and discussion}

In line with the aims of the current research, the results of Bayesian state-space GSPM from MCMC simulations are briefly presented in Tables 3-4 and Figures 2-3 for the fourteen specified high-commercial demersal fish species in the study area. In addition, the related results are described and discussed as follows:

\section{Convergence to posterior distribution}

Table 2 presents the outcomes of three tests for model diagnosis about convergence and stationarity (Plummer et al. 2006).

In the first place, the Geweke diagnostic test was separately applied to verify convergence of the mean of each parameter obtained from the sampled values related to each single chain. In the following, the derived $\mathrm{Z}$-score indicates convergence if its values be less than 2 at absolute value. Thus, as shown in Table 2, for three MCMC chains of all fourteen specified high-commercial demersal fish species, the absolute value of $\mathrm{Z}$-scores is less than 2 which demonstrates that there are no considerable differences in the means of the first and last collections of iterations of the chains. Secondly, the potential scale reduction factor of the Gelman-Rubin diagnostic $(\hat{R})$ is used to investigate the convergence of the chain applying two or more samples produced in parallel. The $\hat{R}$ values, approximately close to one, which reveal convergence shows that all MCMC samples of the model parameters reached convergence to posterior distributions. Therefore, according to the results, the $\hat{R}$ values are identically one for all the above-mentioned fish species MCMC chains, which are consistent with the convergence in distribution of the MCMC samples to the posterior distributions. The third diagnostic statistic, the Heidelberger-Welch stationarity test, was used to explore the sample convergence of single chains from univariate observations, expressed by p-values. Hence, considering the results, the MCMC chains of all the fish species MCMC simulations passed the Heidelberger and Welch stationarity test, which could not reject the hypothesis that the MCMC chains are stationary at the $95 \%$ confidence level for any of the parameters. Generally, the above-described diagnostic convergence tests and visual consideration of trace plots in Appendix 2, confirm that the MCMC chains of all fourteen specified high-commercial demersal fish species produce representative specimens from the joint posterior distribution over the model parameters. 


\begin{tabular}{|c|c|c|c|c|c|c|c|c|c|c|c|c|c|c|c|c|}
\hline \multirow{9}{*}{ 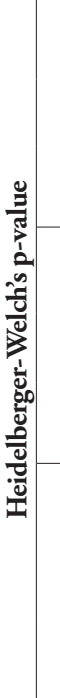 } & \multirow{3}{*}{. } & ฮ్ల్ & $\stackrel{\leftrightarrow}{\circ}$ & $\stackrel{+}{\circ}$ & $\mid \begin{array}{l}\infty \\
0 \\
0 \\
0\end{array}$ & $\overrightarrow{\hat{0}}$ & 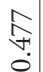 & $\widehat{6}$ & $\frac{7}{\forall}$ & $\begin{array}{l}\vec{\sigma} \\
\dot{0}\end{array}$ & 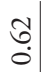 & 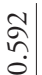 & $\hat{\tilde{n}}$ & $\stackrel{\infty}{+\infty}$ & $\begin{array}{l}\vec{b} \\
0\end{array}$ & $\tilde{o}$ \\
\hline & & $\sum^{\frac{v}{2}}$ & $\hat{\sigma}$ & $\begin{array}{l}\infty \\
\stackrel{0}{0} \\
\end{array}$ & $\grave{\partial}$ & ळे & 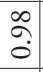 & $\grave{\delta}$ & ळे & 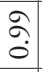 & ळे & $\grave{\partial}$ & $\begin{array}{l}\infty \\
\stackrel{0}{0}\end{array}$ & $\tilde{\sigma}$ & $\begin{array}{l}\infty \\
\stackrel{a}{0}\end{array}$ & $\begin{array}{l} \\
\swarrow \\
\vdots\end{array}$ \\
\hline & & $\stackrel{5}{\Sigma}$ & $\begin{array}{l}\hat{\widehat{O}} \\
\text { Oे }\end{array}$ & $\begin{array}{l}n \\
2 \\
0 \\
0\end{array}$ & $\begin{array}{l}\tilde{N} \\
\tilde{0} \\
0\end{array}$ & 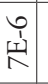 & ô. & $\begin{array}{l}0 \\
\vdots \\
0 \\
\vdots\end{array}$ & $\begin{array}{l}\overrightarrow{0} \\
0 \\
0\end{array}$ & $\begin{array}{l}0 \\
\vdots \\
0\end{array}$ & $\begin{array}{l} \\
\vdots \\
0 \\
0\end{array}$ & $\begin{array}{l}0 \\
\vdots \\
0 \\
0\end{array}$ & $\begin{array}{l}0 \\
\vdots \\
0\end{array}$ & $\begin{array}{l}n \\
0 \\
0\end{array}$ & $\begin{array}{l}1 \\
0 \\
0\end{array}$ & $\begin{array}{l}1 \\
0 \\
0 \\
0\end{array}$ \\
\hline & \multirow{3}{*}{ 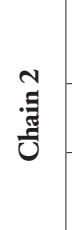 } & ङू & 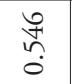 & $\begin{array}{l}\infty \\
\vdots \\
\vdots \\
\vdots\end{array}$ & $\begin{array}{l}m \\
\tilde{n} \\
0\end{array}$ & \begin{tabular}{l|}
\multirow{2}{\infty}{} \\
\multirow{2}{+}{} \\
0
\end{tabular} & 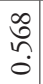 & $\begin{array}{l}\frac{7}{n} \\
\tilde{0}\end{array}$ & $\stackrel{*}{*}$ & $\stackrel{+}{\stackrel{+}{0}}$ & ఫे & $\begin{array}{l}\stackrel{0}{2} \\
\stackrel{+}{+} \\
0\end{array}$ & $\stackrel{+}{n}$ & ڤે & $\tilde{o}$ & $\begin{array}{c}n \\
\exists \\
0 \\
0\end{array}$ \\
\hline & & $\sum^{\stackrel{.}{\pi}}$ & oे & $\stackrel{2}{\varrho}$ & $\bar{\sigma}$ & ఠ. & $\grave{\partial}$ & $\hat{\sigma}$ & 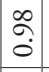 & $\grave{\partial}$ & $\tilde{\sigma}$ & ఏ. & $\hat{\alpha}$ & ळे & $\grave{0}$ & ळ. \\
\hline & & $\stackrel{5}{\Sigma}$ & $\begin{array}{l}n \\
\dot{0}\end{array}$ & \begin{tabular}{l}
\multirow{2}{*}{} \\
$\tilde{0}$ \\
0
\end{tabular} & $\mid \begin{array}{l}\infty \\
0 \\
0 \\
0\end{array}$ & $\begin{array}{l}n \\
0 \\
0\end{array}$ & $\begin{array}{l}\hat{\sigma} \\
8 \\
0\end{array}$ & $\begin{array}{l}n \\
\dot{0} \\
\dot{0}\end{array}$ & $\begin{array}{l}n \\
0 \\
0\end{array}$ & $\begin{array}{l}\stackrel{0}{0} \\
\stackrel{0}{0}\end{array}$ & $\begin{array}{l}\hat{0} \\
0\end{array}$ & $\begin{array}{l}n \\
0 \\
0\end{array}$ & $\begin{array}{l}\hat{0} \\
\dot{0}\end{array}$ & $\hat{8}$ & $\begin{array}{l}n \\
0 \\
0\end{array}$ & $\begin{array}{l}n \\
0 \\
0\end{array}$ \\
\hline & \multirow{3}{*}{ 鴣 } & $\sum^{\tilde{\Xi}}$ & $\infty$ & \begin{tabular}{l}
0 \\
\multirow{2}{*}{} \\
0 \\
0
\end{tabular} & \begin{tabular}{l}
\multirow{2}{*}{} \\
\multirow{0}{0}{} \\
\end{tabular} & $\begin{array}{l}\hat{\sigma} \\
\dot{0}\end{array}$ & $\begin{array}{l}\sigma \\
\overrightarrow{0} \\
\stackrel{0}{0}\end{array}$ & $\begin{array}{l}\text { ज़े } \\
\text { ¿ी }\end{array}$ & $\begin{array}{l}\vec{\sigma} \\
\text { o. }\end{array}$ & సે. & $\hat{0}$ & $\begin{array}{l}\text { స్ర } \\
0\end{array}$ & $\underset{+}{\stackrel{+}{0}}$ & ? & $\tilde{o}$ & $\begin{array}{l}0 \\
\tilde{n} \\
0\end{array}$ \\
\hline & & $\sum_{\Sigma}^{\stackrel{x}{\pi}}$ & $\grave{o}$ & $\grave{0}$ & $\tilde{\sigma}$ & $\grave{\Omega}$ & $\grave{\partial}$ & $\begin{array}{l}\infty \\
\vdots \\
\vdots\end{array}$ & $\begin{array}{l}\infty \\
\stackrel{2}{0} \\
\end{array}$ & $\grave{\partial}$ & $\grave{\partial}$ & $\begin{array}{l}\infty \\
\check{0}\end{array}$ & $\grave{\partial}$ & $\hat{0}$ & $\grave{0}$ & $\begin{array}{l}\infty \\
\vdots \\
\vdots\end{array}$ \\
\hline & & $\stackrel{5}{\Sigma}$ & ঃ & \begin{tabular}{|l} 
\pm \\
$\vdots$ \\
0 \\
0
\end{tabular} & $\mid$\begin{tabular}{|}
+ \\
0 \\
0 \\
0
\end{tabular} & $\begin{array}{c}m \\
0 \\
0\end{array}$ & $\begin{array}{l}\hat{\theta} \\
8 \\
0 \\
0\end{array}$ & $\overrightarrow{0}$ & $\begin{array}{l}n \\
0 \\
0\end{array}$ & $\begin{array}{l}n \\
0 \\
0\end{array}$ & $\begin{array}{l}\overrightarrow{0} \\
0\end{array}$ & $\begin{array}{l}\hat{8} \\
\dot{0} \\
\dot{0}\end{array}$ & $\begin{array}{l}n \\
0 \\
0\end{array}$ & $\begin{array}{l}n \\
0 \\
0\end{array}$ & $\begin{array}{l}n \\
\tilde{0} \\
0\end{array}$ & $\begin{array}{l}\qquad \\
0 \\
0 \\
0\end{array}$ \\
\hline \multirow{3}{*}{ 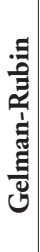 } & \multirow{3}{*}{ 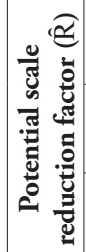 } & 赵 & - & -1 & -1 & -1 & - & -1 & -7 & - & -1 & -1 & - & - & -1 & - \\
\hline & & 莽 $N$ & 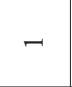 & -1 & -1 & - & - & - & - & - & - & - & -1 & - & -1 & - \\
\hline & & - & - & -1 & -1 & -1 & - & -1 & -1 & - & - & - & - & - & -1 & - \\
\hline \multirow{9}{*}{ 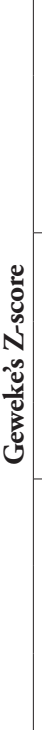 } & \multirow{3}{*}{ 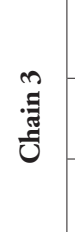 } & $\sum^{\tilde{E}}$ & & $\begin{array}{c}2 \\
\stackrel{2}{2} \\
0\end{array}$ & స̃ & $\begin{array}{l}\hat{0} \\
+ \\
0 \\
0\end{array}$ & 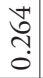 & 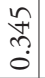 & $\begin{array}{c}\tilde{O} \\
0 \\
0\end{array}$ & 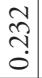 & 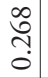 & $\begin{array}{l}1 \\
0 \\
\dot{i} \\
\end{array}$ & $\begin{array}{c}0 \\
\stackrel{1}{0} \\
0\end{array}$ & $\begin{array}{l}\stackrel{+}{0} \\
\text { ஸे }\end{array}$ & 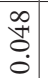 & $\begin{array}{l}n \\
\tilde{o} \\
\dot{0}\end{array}$ \\
\hline & & $\sum_{\Sigma}^{\frac{\pi}{J}}$ & & 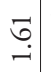 & \begin{tabular}{|l|} 
\\
\\
\end{tabular} & $\sqrt[\widetilde{n}]{-}$ & $\stackrel{\forall}{-}$ & $\stackrel{\leftrightarrow}{\rightarrow}$ & 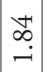 & 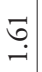 & \begin{tabular}{|l|} 
\\
\\
\\
\end{tabular} & $\stackrel{\infty}{-}$ & $\underset{\sim}{\stackrel{+}{\sim}}$ & $\stackrel{n}{\stackrel{n}{r}}$ & $\stackrel{\hat{\sigma}}{-}$ & $\stackrel{n}{\stackrel{n}{-}}$ \\
\hline & & $\stackrel{\Xi}{\Sigma}$ & $\mathbb{N}$ & \begin{tabular}{|c|} 
\\
\\
-1 \\
\end{tabular} & \begin{tabular}{|l|} 
\\
\\
\end{tabular} & 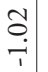 & 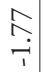 & $\stackrel{+}{+}$ & 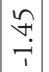 & $\stackrel{n}{\rightarrow}$ & \begin{tabular}{|c|}
$\infty$ \\
$\infty$ \\
\\
\end{tabular} & $\begin{array}{l} \pm \\
\stackrel{+}{\top} \\
\end{array}$ & \begin{tabular}{|l|}
$\infty$ \\
0 \\
\\
\end{tabular} & $\underset{i}{\stackrel{\leftrightarrow}{i}}$ & & $\begin{array}{l}n \\
\stackrel{n}{i} \\
i\end{array}$ \\
\hline & \multirow{3}{*}{ 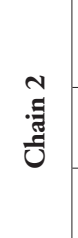 } & $\sum^{\tilde{\Xi}}$ & & $\begin{array}{l}0 \\
\dot{0} \\
\end{array}$ & 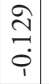 & $\begin{array}{l}n \\
0 \\
\dot{\varphi}\end{array}$ & 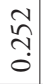 & $\begin{array}{l}\infty \\
\infty \\
\rightarrow 0\end{array}$ & $=$ & 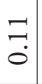 & 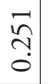 & ڤై & $\begin{array}{l}\hat{8} \\
\dot{0}\end{array}$ & $\begin{array}{l}\text { Iิ } \\
\stackrel{7}{0}\end{array}$ & $\stackrel{7}{\circ}$ & 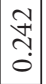 \\
\hline & & $\sum^{\frac{.}{z}}$ & & $\mid \begin{array}{c}\infty \\
0 \\
- \\
-\end{array}$ & $\begin{array}{l}\infty \\
+ \\
\stackrel{-}{-} \\
\end{array}$ & $\begin{array}{l}\stackrel{\sim}{\sigma} \\
- \\
-\end{array}$ & $\stackrel{\sim}{\sim}$ & $\stackrel{n}{-}$ & $\stackrel{n}{-}$ & 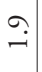 & $\stackrel{n}{-}$ & $\stackrel{n}{-}$ & $\stackrel{\infty}{\stackrel{\infty}{-}}$ & $\stackrel{\leftrightarrow}{\hat{\sigma}}$ & $\vec{\Im}$ & $\stackrel{N}{\underset{i}{\mathrm{~N}}}$ \\
\hline & & 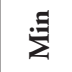 & & 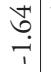 & 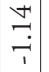 & & $\begin{array}{l}n \tilde{n} \\
\frac{n}{i}\end{array}$ & $\underset{-}{\overrightarrow{0}}$ & 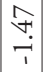 & $\stackrel{n}{\stackrel{n}{-}}$ & \begin{tabular}{l}
$\tilde{\sigma}$ \\
\hdashline \\
1
\end{tabular} & : & $\begin{array}{l}\infty \\
\stackrel{-}{\longrightarrow} \\
\end{array}$ & $\stackrel{m}{\longrightarrow}$ & $\underset{1}{\stackrel{\overbrace{}}{1}}$ & $\stackrel{\sim}{\sim}$ \\
\hline & \multirow{3}{*}{ 胥 } & $\sum^{\tilde{\Xi}}$ & & 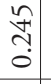 & 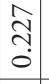 & $\begin{array}{l}\stackrel{2}{0} \\
\stackrel{0}{\circ}\end{array}$ & $\begin{array}{l}\infty \\
0 \\
0 \\
0\end{array}$ & $\begin{array}{l}n \\
\sigma \\
0\end{array}$ & $\begin{array}{c}\vec{\infty} \\
\overrightarrow{0} \\
\end{array}$ & $=$ & $\begin{array}{l}\infty \\
0 \\
0 \\
\end{array}$ & 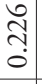 & $\begin{array}{l}\tilde{\delta} \\
\stackrel{\delta}{0}\end{array}$ & $\stackrel{\overrightarrow{0}}{0}$ & $\stackrel{m}{0}$ & 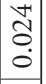 \\
\hline & & $\sum^{\frac{\pi}{\sigma}}$ & & 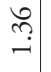 & $\stackrel{0}{=}$ & $\begin{array}{l}\vec{\Xi} \\
\end{array}$ & 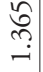 & $\Im$ & $\stackrel{\infty}{\stackrel{-}{-}}$ & $\begin{array}{l}\stackrel{0}{\sim} \\
\sim\end{array}$ & $\bar{\Xi}$ & $\stackrel{\vartheta}{-}$ & $=$ & $\stackrel{\Xi}{\leftrightarrows}$ & $\stackrel{\widetilde{n}}{\check{\imath}}$ & 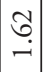 \\
\hline & & 至 & $\Re$ & $\stackrel{\uparrow}{-}$ & ᄁֶ. & $\stackrel{m}{\rightarrow}$ & 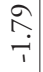 & $\begin{array}{c}\infty \\
\infty \\
-1\end{array}$ & $\left|\begin{array}{c}0 \\
\stackrel{1}{i} \\
i\end{array}\right|$ & 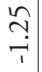 & 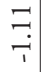 & તิ & $\begin{array}{l}\infty \\
\stackrel{\infty}{\longrightarrow} \\
\rightarrow\end{array}$ & $\stackrel{\overbrace{}}{\leftrightarrows}$ & 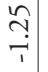 & $\begin{array}{c}\stackrel{\partial}{\infty} \\
\stackrel{i}{1}\end{array}$ \\
\hline \multicolumn{3}{|c|}{$\begin{array}{l}\text { कूँّ } \\
\text { के }\end{array}$} & 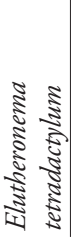 & 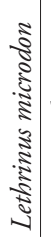 & $\mid$ & 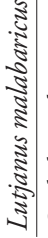 & 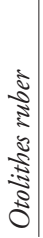 & $\begin{array}{l}3 \\
3 \\
0 \\
0 \\
5 \\
5 \\
3 \\
3\end{array}$ & 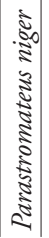 & 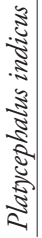 & 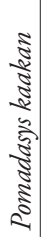 & 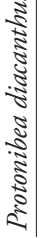 & 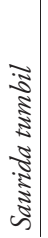 & 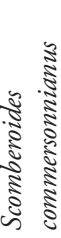 & 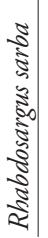 & 离 \\
\hline
\end{tabular}




\section{Estimates of model parameters}

Summary of the posterior descriptive statistics is presented in Table 3, including the posterior means and marginal posteriors with $95 \%$ credibility intervals (Crl) (the $2.5 \%$ and $97.5 \%$ percentiles as lower and upper limits) for Bayesian state-space GSPM parameters of the fourteen specified high-commercial demersal fish species.

Since the intrinsic growth rate $r$ shows the relationship between size and age, it is an important factor in life history theory (Arendt 1997). The marginal posterior means of the intrinsic growth rate (r) for Elutheronema tetradactylum within $95 \%$ credibility intervals $(0.051,0.332)$ indicated that the given available data information (prior distribution) and the true value of (r) falls within (Crl) with $95 \%$ probability. Similarly, for all other thirteen fish species, the marginal posterior means of (r) were within $95 \%$ credibility intervals of the posterior predictive distributions and it can be concluded that, for the given available data information (prior distribution), the true value of (r) falls within (Crl) $95 \%$ probability for them. The posterior means of intrinsic growth rate for Platycephalus indicus and Scomberoides commersonnianus were similar to results attained by Cheung and Sumaila (2015), but for all the other 11 remaining fish species, except for Protonibea diacanthus, the posterior means of intrinsic growth were lower and, for Protonibea diacanthus, it was more than the results of the recently above-mentioned study. The posterior means of all the fish species more than medians indicates that their posterior distributions right skewed. Since the mean and median of posterior distribution of (r) for all fish species was within $95 \%(\mathrm{Crl})$, therefore for the given available data information (prior distribution), the true value of (r) falls within (Crl) with $95 \%$ probability.

According to the results in Table 3, the marginal posterior means of shape parameter, (z), for Elutheronema tetradactylum was within the 95\% credibility intervals $(0.112,2.736)$, indicating that, for the given available data information (prior distribution), the true value of (z) falls within ( $\mathrm{Crl})$ with $95 \%$ probability. Similarly, for all other thirteen fish species, the marginal posterior means of $(\mathrm{z})$ were within the $95 \%$ credibility intervals of the posterior predictive distributions and it can be concluded that, for the given available data information (prior distribution), the true value of (z) falls within (Crl) with the $95 \%$ probability for them. In addition, based on the results, for all Bayesian state-space GSPM, the marginal posterior means for $(z)$, with 95\% credible interval, were dissimilar and the posterior means greater than medians indicated that the related posterior distributions were right skewed. The posterior means of shape parameter $z$ for Platycephalus indicus and Scomberoides commersonnianus were more than unity and indicates that the biomass production was increased into peak when the biomass was more than $\mathrm{K} / 2$. However, for all the other remaining 12 fish species, the posterior means and medians of shape parameter $z$ were less than unity, indicating that the biomass production peaked when the biomass was less than $\mathrm{K} / 2$. As mentioned above and according to the results of Table 3, although the value of the shape parameter $z$ is different from unity for all 14 models, due to the proximity of the value of $z$ with unity, it may be assumed that the classic Schaefer (logistic) surplus 
Table 3. A summary of the posterior descriptive statistics for bayesian state-space GSPM parameters of fourteen specified high-commercial demersal fish species.

\begin{tabular}{|c|c|c|c|c|c|c|c|c|}
\hline \multirow{2}{*}{\multicolumn{2}{|c|}{ Parameter }} & \multicolumn{7}{|c|}{ Species } \\
\hline & & \multirow{2}{*}{$\begin{array}{c}\begin{array}{c}\text { Elutheronema } \\
\text { tetradactylum }\end{array} \\
0.329 \\
\end{array}$} & \multirow{2}{*}{$\begin{array}{c}\begin{array}{c}\text { Lethrinus } \\
\text { microdon }\end{array} \\
0.727 \\
\end{array}$} & \multirow{2}{*}{$\begin{array}{c}\begin{array}{c}\text { Lutjanus } \\
\text { johni }\end{array} \\
0.248 \\
\end{array}$} & \multirow{2}{*}{$\begin{array}{c}\begin{array}{c}\text { Lutjanus } \\
\text { malabaricus }\end{array} \\
0.298 \\
\end{array}$} & \multirow{2}{*}{$\begin{array}{c}\begin{array}{c}\text { Otolithes } \\
\text { ruber }\end{array} \\
0.152 \\
\end{array}$} & \multirow{2}{*}{$\begin{array}{c}\begin{array}{c}\text { Pampus } \\
\text { argenteus }\end{array} \\
0.612 \\
\end{array}$} & \multirow{2}{*}{$\begin{array}{c}\text { Parastromateus } \\
\text { niger }\end{array}$} \\
\hline \multirow{6}{*}{ r } & Mean & & & & & & & \\
\hline & S.D. & 0.141 & 0.286 & 0.113 & 0.134 & 0.074 & 0.279 & 0.161 \\
\hline & MC error & 0.001 & 0.004 & 0.001 & 0.001 & $9.8 \mathrm{E}-4$ & 0.002 & 0.001 \\
\hline & Perc. $2.5 \%$ & 0.126 & 0.295 & 0.09 & 0.111 & 0.054 & 0.223 & 0.124 \\
\hline & Median & 0.304 & 0.688 & 0.223 & 0.273 & 0.137 & 0.558 & 0.306 \\
\hline & Perc. $97.5 \%$ & 0.668 & 1.393 & 0.529 & 0.627 & 0.336 & 1.295 & 0.748 \\
\hline \multirow{6}{*}{ K } & Mean & 1058 & 1530 & 1995 & 1110 & 5175 & 1409 & 12080 \\
\hline & S.D. & 365.6 & 370 & 623.6 & 353 & 908.7 & 553.5 & 5477 \\
\hline & MC error & 2.726 & 3.717 & 6.953 & 2.64 & 18.11 & 5.416 & 51.99 \\
\hline & Perc. $2.5 \%$ & 621.5 & 1104 & 1214 & 718.1 & 4215 & 634.5 & 6602 \\
\hline & Median & 975.7 & 1438 & 1865 & 1017 & 4918 & 1318 & 10450 \\
\hline & Perc. $97.5 \%$ & 1975 & 2463 & 3526 & 2018 & 7565 & 2736 & 26630 \\
\hline \multirow{6}{*}{$q$} & Mean & 0.001 & 0.001 & 0.001 & 0.001 & 0.001 & 0.001 & $5.5 \mathrm{E}-4$ \\
\hline & S.D. & $5 \mathrm{E}-4$ & $3 \mathrm{E}-4$ & $4.4 \mathrm{E}-4$ & $4.2 \mathrm{E}-4$ & $1.5 \mathrm{E}-4$ & $7.2 \mathrm{E}-4$ & $1.9 \mathrm{E}-4$ \\
\hline & MC error & $4 \mathrm{E}-6$ & $3 \mathrm{E}-6$ & $4.5 \mathrm{E}-6$ & $3 \mathrm{E}-6$ & $3 \mathrm{E}-6$ & $6.5 \mathrm{E}-6$ & $1.7 \mathrm{E}-6$ \\
\hline & Perc. $2.5 \%$ & $8 \mathrm{E}-4$ & $8.8 \mathrm{E}-4$ & $8.4 \mathrm{E}-4$ & $8.3 \mathrm{E}-4$ & $6.9 \mathrm{E}-4$ & $8.5 \mathrm{E}-4$ & $2 \mathrm{E}-4$ \\
\hline & Median & 0.001 & 0.001 & 0.001 & 0.001 & 0.001 & 0.001 & $5.5 \mathrm{E}-4$ \\
\hline & Perc. $97.5 \%$ & 0.002 & 0.002 & 0.002 & 0.002 & 0.001 & 0.003 & $9.2 \mathrm{E}-4$ \\
\hline \multirow{6}{*}{$\mathrm{z}$} & Mean & 0.953 & 0.89 & 0.995 & 0.96 & 0.993 & 0.987 & 0.983 \\
\hline & S.D. & 0.708 & 0.661 & 0.709 & 0.688 & 0.695 & 0.712 & 0.698 \\
\hline & MC error & 0.006 & 0.008 & 0.008 & 0.005 & 0.012 & 0.006 & 0.005 \\
\hline & Perc. $2.5 \%$ & 0.112 & 0.108 & 0.119 & 0.117 & 0.122 & 0.118 & 0.121 \\
\hline & Median & 0.779 & 0.723 & 0.829 & 0.795 & 0.84 & 0.821 & 0.82 \\
\hline & Perc. $97.5 \%$ & 2.736 & 2.604 & 2.808 & 2.707 & 2.728 & 2.776 & 2.766 \\
\hline \multirow{6}{*}{$\sigma^{2}$} & Mean & 0.007 & 0.007 & 0.008 & 0.007 & 0.007 & 0.007 & $2.5 \mathrm{E}-4$ \\
\hline & S.D. & 0.002 & 0.002 & 0.002 & 0.002 & 0.002 & 0.002 & $1.4 \mathrm{E}-4$ \\
\hline & MC error & $1.2 \mathrm{E}-5$ & $1.5 \mathrm{E}-5$ & $1.6 \mathrm{E}-5$ & $1 \mathrm{E}-5$ & $1.3 \mathrm{E}-5$ & $1.4 \mathrm{E}-5$ & $8.7 \mathrm{E}-7$ \\
\hline & Perc. $2.5 \%$ & 0.004 & 0.004 & 0.004 & 0.004 & 0.004 & 0.004 & $9.8 \mathrm{E}-5$ \\
\hline & Median & 0.006 & 0.007 & 0.008 & 0.006 & 0.007 & 0.007 & $2 \mathrm{E}-5$ \\
\hline & Perc. $97.5 \%$ & 0.012 & 0.014 & 0.015 & 0.012 & 0.012 & 0.139 & $6.3 \mathrm{E}-4$ \\
\hline \multirow{6}{*}{$\tau^{2}$} & Mean & 0.358 & 0.071 & 0.021 & 0.459 & 0.012 & 0.079 & 0.121 \\
\hline & S.D. & 0.105 & 0.023 & 0.007 & 0.134 & 0.004 & 0.025 & 0.045 \\
\hline & MC error & $6 \mathrm{E}-4$ & $1.3 \mathrm{E}-4$ & $4.8 \mathrm{E}-5$ & $8 \mathrm{E}-4$ & $2.5 \mathrm{E}-5$ & $1.3 \mathrm{E}-4$ & $3.2 \mathrm{E}-4$ \\
\hline & Perc. $2.5 \%$ & 0.206 & 0.037 & 0.009 & 0.266 & 0.006 & 0.042 & 0.06 \\
\hline & Median & 0.341 & 0.068 & 0.02 & 0.437 & 0.012 & 0.075 & 0.112 \\
\hline & Perc. $97.5 \%$ & 0.613 & 0.127 & 0.04 & 0.785 & 0.023 & 0.139 & 0.236 \\
\hline
\end{tabular}

production model (SSPM) is a better option than the generalised surplus production model (GSPM). Therefore, the (SSPM) was estimated for all aforesaid fourteen studied fish species and compared with (GSPM) based on predictive performance using the Deviance Information Criterion (DIC), given by Spiegelhalter et al. 2002. In addition, according to Ando (2010), DIC is used to compare the performance of different Bayesian models. It is particularly useful where the posterior distributions of the mod- 
Table 3. Continued.

\begin{tabular}{|c|c|c|c|c|c|c|c|c|}
\hline \multirow{2}{*}{\multicolumn{2}{|c|}{ Parameter }} & \multicolumn{7}{|c|}{ Species } \\
\hline & & \multirow{2}{*}{$\begin{array}{c}\begin{array}{c}\text { Platycephalus } \\
\text { indicus }\end{array} \\
0.145 \\
\end{array}$} & \multirow{2}{*}{\begin{tabular}{|c|}
$\begin{array}{c}\text { Pomadasys } \\
\text { kaakan }\end{array}$ \\
1.173 \\
\end{tabular}} & \multirow{2}{*}{\begin{tabular}{|c|}
$\begin{array}{c}\text { Protonibea } \\
\text { diacanthus }\end{array}$ \\
0.474 \\
\end{tabular}} & \multirow{2}{*}{\begin{tabular}{|c|}
$\begin{array}{c}\text { Saurida } \\
\text { tumbil }\end{array}$ \\
0.411 \\
\end{tabular}} & \multirow{2}{*}{\begin{tabular}{|c|c|}
$\begin{array}{c}\text { Scomberoides } \\
\text { commersonnianus }\end{array}$ \\
0.247
\end{tabular}} & \multirow{2}{*}{\begin{tabular}{|c|}
$\begin{array}{c}\text { Rhabdosargus } \\
\text { sarba }\end{array}$ \\
0.378 \\
\end{tabular}} & \multirow{2}{*}{\begin{tabular}{|c|}
$\begin{array}{c}\text { Trachinotu } \\
\text { mookalee }\end{array}$ \\
0.175 \\
\end{tabular}} \\
\hline \multirow{6}{*}{$\mathrm{r}$} & Mean & & & & & & & \\
\hline & S.D. & 0.073 & 0.567 & 0.328 & 0.201 & 0.124 & 0.175 & 0.079 \\
\hline & MC error & $8.3 \mathrm{E}-4$ & 0.004 & 0.009 & 0.002 & 0.001 & 0.002 & $7.6 \mathrm{E}-4$ \\
\hline & Perc. $2.5 \%$ & 0.051 & 0.42 & 0.142 & 0.146 & 0.087 & 0.136 & 0.066 \\
\hline & Median & 0.13 & 1.057 & 0.377 & 0.369 & 0.221 & 0.343 & 0.16 \\
\hline & Perc. $97.5 \%$ & 0.332 & 2.598 & 1.314 & 0.92 & 0.561 & 0.806 & 0.367 \\
\hline \multirow{6}{*}{ K } & Mean & 1609 & 4015 & 6641 & 2580 & 11630 & 2146 & 1121 \\
\hline & S.D. & 445.7 & 902.6 & 1876 & 390.6 & 616.1 & 365.3 & 336 \\
\hline & MC error & 4.183 & 6.027 & 28.51 & 4.339 & 6.865 & 4.086 & 2.851 \\
\hline & Perc. $2.5 \%$ & 1095 & 3022 & 4504 & 2182 & 11020 & 1758 & 727.4 \\
\hline & Median & 1498 & 3771 & 6149 & 2466 & 11450 & 2042 & 1041 \\
\hline & Perc. $97.5 \%$ & 2734 & 6334 & 11510 & 3607 & 13270 & 3109 & 1971 \\
\hline \multirow{6}{*}{ q } & Mean & 0.001 & 0.001 & 0.001 & $9.5 \mathrm{E}-4$ & $4.3 \mathrm{E}-4$ & 0.001 & 0.001 \\
\hline & S.D. & $3.4 \mathrm{E}-4$ & $2.5 \mathrm{E}-4$ & $3.2 \mathrm{E}-4$ & $1.3 \mathrm{E}-4$ & $3.2 \mathrm{E}-5$ & $1.6 \mathrm{E}-4$ & $4 \mathrm{E}-4$ \\
\hline & MC error & $3 \mathrm{E}-6$ & $1.6 \mathrm{E}-6$ & 4.9E-6 & $1.5 \mathrm{E}-6$ & $5 \mathrm{E}-7$ & $1.8 \mathrm{E}-6$ & $3.2 \mathrm{E}-6$ \\
\hline & Perc. $2.5 \%$ & $8 \mathrm{E}-4$ & 7.7E-4 & $6.8 \mathrm{E}-4$ & 6.6E-4 & $3.6 \mathrm{E}-4$ & $6.9 \mathrm{E}-4$ & $8.4 \mathrm{E}-4$ \\
\hline & Median & 0.001 & 0.001 & 0.001 & $9.5 \mathrm{E}-4$ & $4.3 \mathrm{E}-4$ & 0.001 & 0.001 \\
\hline & Perc. $97.5 \%$ & 0.002 & 0.001 & 0.001 & 0.001 & $4.9 \mathrm{E}-4$ & 0.001 & 0.002 \\
\hline \multirow{6}{*}{$\mathrm{z}$} & Mean & 1.001 & 0.996 & 1.047 & 1.006 & 0.982 & 0.993 & 0.965 \\
\hline & S.D. & 0.704 & 0.699 & 0.72 & 0.73 & 0.691 & 0.701 & 0.711 \\
\hline & MC error & 0.005 & 0.005 & 0.01 & 0.011 & 0.012 & 0.007 & 0.005 \\
\hline & Perc. $2.5 \%$ & 0.12 & 0.118 & 0.131 & 0.118 & 0.12 & 0.117 & 0.109 \\
\hline & Median & 0.842 & 0.838 & 0.89 & 0.836 & 0.824 & 0.832 & 0.792 \\
\hline & Perc. $97.5 \%$ & 2.774 & 2.752 & 2.869 & 2.824 & 2.726 & 2.765 & 2.803 \\
\hline \multirow{6}{*}{$\sigma^{2}$} & Mean & 0.007 & 0.007 & 0.008 & 0.008 & 0.008 & 0.008 & 0.007 \\
\hline & S.D. & 0.002 & 0.002 & 0.003 & 0.002 & 0.003 & 0.003 & 0.002 \\
\hline & MC error & $1.6 \mathrm{E}-5$ & $1.4 \mathrm{E}-5$ & $2.3 \mathrm{E}-5$ & $1.5 \mathrm{E}-5$ & $1.8 \mathrm{E}-5$ & $1.8 \mathrm{E}-5$ & $1.2 \mathrm{E}-5$ \\
\hline & Perc. 2.5\% & 0.004 & 0.004 & 0.004 & 0.004 & 0.004 & 0.004 & 0.004 \\
\hline & Median & 0.007 & 0.007 & 0.008 & 0.007 & 0.008 & 0.007 & 0.007 \\
\hline & Perc. $97.5 \%$ & 0.014 & 0.013 & 0.017 & 0.014 & 0.016 & 0.015 & 0.012 \\
\hline \multirow{6}{*}{$\tau^{2}$} & Mean & 0.068 & 0.082 & 0.027 & 0.056 & 0.028 & 0.046 & 0.145 \\
\hline & S.D. & 0.022 & 0.026 & 0.01 & 0.019 & 0.011 & 0.016 & 0.044 \\
\hline & MC error & $1.3 \mathrm{E}-4$ & $1.4 \mathrm{E}-4$ & $1 \mathrm{E}-4$ & $1 \mathrm{E}-4$ & $7.6 \mathrm{E}-5$ & $9.9 \mathrm{E}-5$ & $2.4 \mathrm{E}-4$ \\
\hline & Perc. $2.5 \%$ & 0.035 & 0.044 & 0.01 & 0.028 & 0.012 & 0.022 & 0.08 \\
\hline & Median & 0.064 & 0.078 & 0.026 & 0.053 & 0.026 & 0.044 & 0.138 \\
\hline & Perc. $97.5 \%$ & 0.122 & 0.146 & 0.053 & 0.102 & 0.055 & 0.085 & 0.252 \\
\hline
\end{tabular}

els have been obtained by MCMC algorithm estimation. Therefore, while comparing different possible models for their similar records, lesser values of DIC recommend better predictive capability. Thus, according to the results of Table 4, the value of DIC for all fish species, based on GSPM, is less than that of SSPM. Therefore, GSPM is more suitable for analysing the present study. 

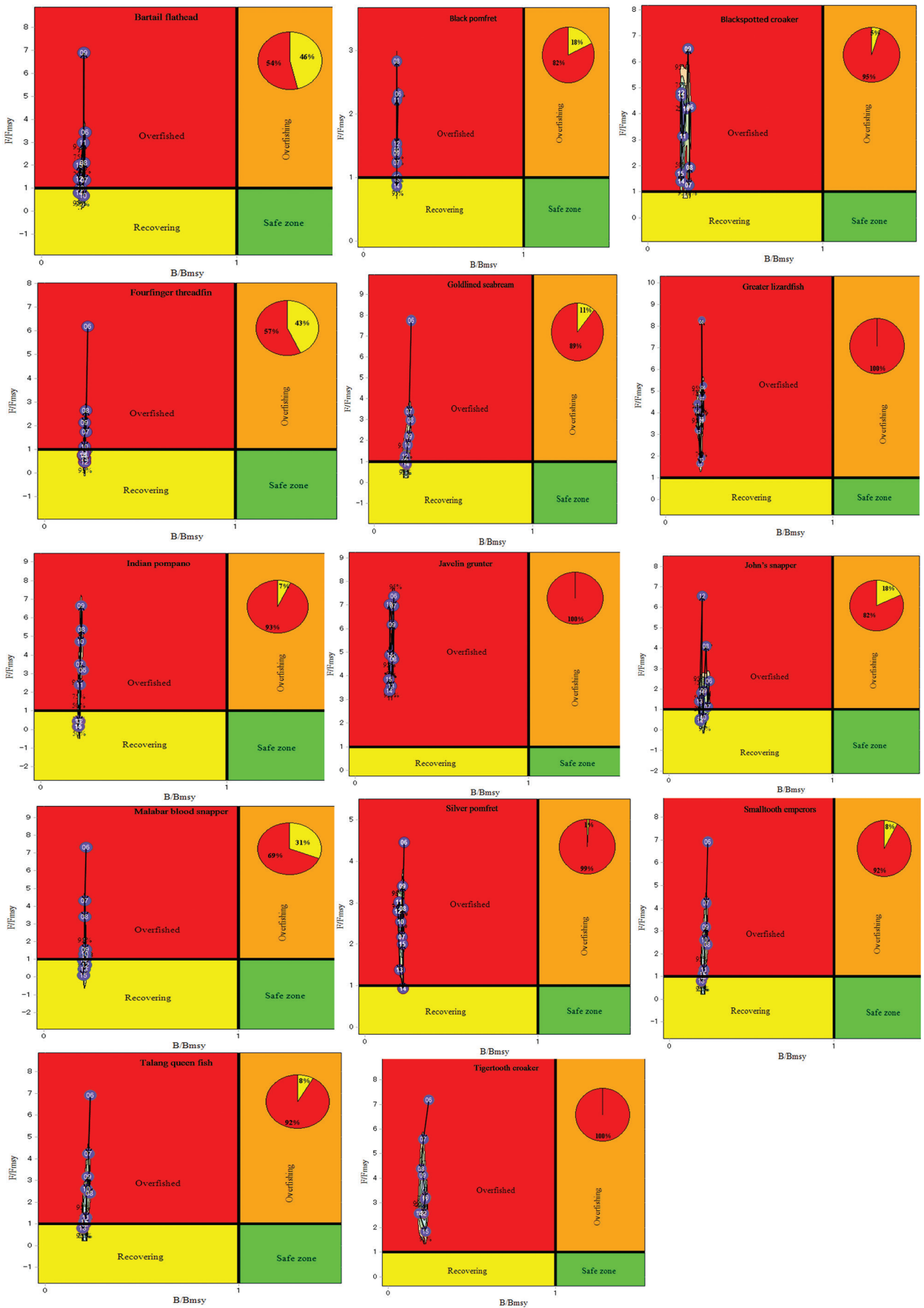

BBmsy

Figure 2. Phase diagram depiction of $\mathrm{F} / \mathrm{F}_{\mathrm{MSY}}$ and $\mathrm{B} / \mathrm{B}_{\mathrm{MSY}}$ for fourteen specified highcommercial demersal fish species, each panel is designate by the common name of the fish at the top. The numbers on purple circles represent the last two digits of the year related to abovementioned ratios. 
The results of Table 3 identify that the marginal posterior means of carrying capacity, $(\mathrm{K})$, for Elutheronema tetradactylum was within the $95 \%$ credibility intervals $(621.5,1975)$ and indicates that, for the given available data information (prior distribution), the true value of $(\mathrm{K})$ falls within $(\mathrm{Crl})$ with $95 \%$ probability. Similarly, for all other thirteen fish species, the marginal posterior means of $(\mathrm{K})$ were within the $95 \%$ credibility intervals of the posterior predictive distributions and it can be concluded that, for the given available data information (prior distribution), the true value of (K) falls within $(\mathrm{Crl})$ with $95 \%$ probability for them. The posterior means of carrying capacity $K$ with $95 \%$ credibility intervals more than the medians as reveals that the posterior distributions right skewed.

The marginal posterior means of the catchability coefficient (q) for Elutheronema tetradactylum was within the $95 \%$ credibility intervals $(0.0008,0.002)$ and indicates that, for the given available data information (prior distribution), the true value of $(\mathrm{q})$ falls within $(\mathrm{Crl})$ with $95 \%$ probability. Similarly, for all other thirteen fish species, the marginal posterior means of (q) were within the $95 \%$ credibility intervals of the posterior predictive distributions and it can be concluded that for the given available data information (prior distribution), the true value of $(\mathrm{q})$ falls within $(\mathrm{Crl})$ with 95\% probability for them. Furthermore, the posterior means and medians of the catchability coefficient $(q)$ with $95 \%$ confidence interval for all the studied fish species were equal which shows that their posterior distributions were symmetric.

The marginal posterior means of the process noise variances, $\left(\Sigma^{2}\right)$ for Elutheronema tetradactylum was within the $95 \%$ credibility intervals $(0.004,0.012)$ and indicates that, for the given available data information (prior distribution), the true value of $\left(\Sigma^{2}\right)$ falls within $(\mathrm{Crl})$ with $95 \%$ probability. Similarly, also, for all other thirteen fish species, the marginal posterior means of $\left(\Sigma^{2}\right)$ were within the $95 \%$ credibility intervals of the posterior predictive distributions and it can be concluded that, for the given available data information (prior distribution), the true value of $\left(\Sigma^{2}\right)$ falls within $(\mathrm{Crl})$ with $95 \%$ probability for them. In addition, for the process noise variances of Bayesian state-space GSPM of Lutjanus malabaricus, Parastromateus niger, Saurida tumbil and Rhabdosargus sarba with 95\% confidence interval, the posterior means were generally higher than the medians because their posterior distributions were right skewed. However, for the other 10 fish species, the posterior means and medians of the process noise variances $\mathrm{o}^{2}$ were equal which shows that their posterior distributions were symmetric.

The marginal posterior means of the observation noise variances, $\left(\tau^{2}\right)$ for Elutheronema tetradactylum within $95 \%$ credibility intervals $(0.206,0.613)$, indicates that for the given available data information (prior distribution), the true value of $\left(\tau^{2}\right)$ falls within (Crl) 95\% probability. Similarly, for all other thirteen fish species, the marginal posterior means of $\left(\tau^{2}\right)$ were within $95 \%$ credibility intervals of the posterior predictive distributions and it can be concluded that, for the given available data information (prior distribution), the true value of $\left(\tau^{2}\right)$ falls within ( $\mathrm{Crl}$ ) with $95 \%$ probability for them. In addition, the means and medians marginal posterior of observation noise variances $\left(\tau^{2}\right)$ of Bayesian state-space GSPM, except for Otolithes ruber, were dissimilar for the other species. For the above-considered fish species, the equality of the poste- 

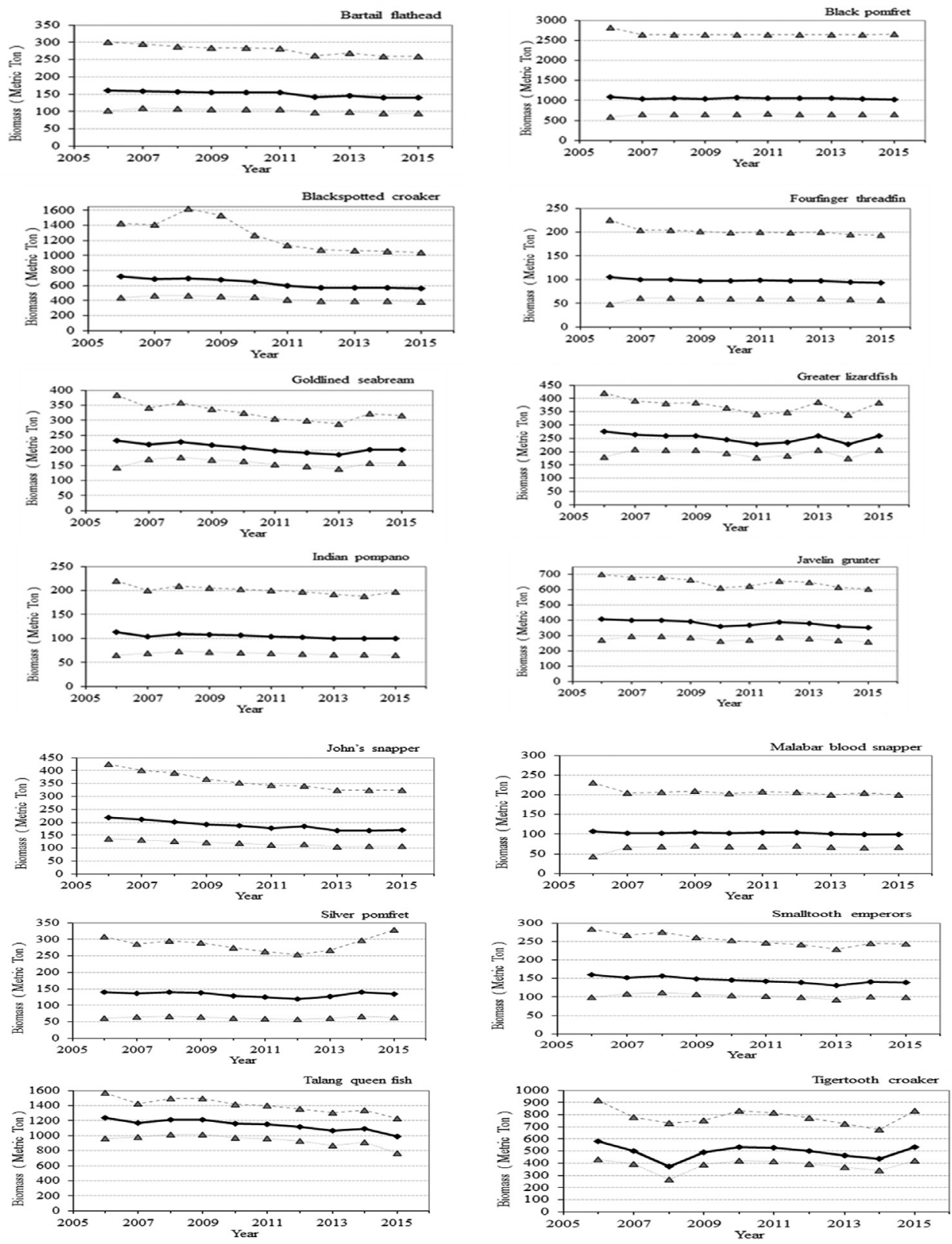

Figure 3. Simulated biomass time series (solid line with squares) of fourteen specified highcommercial demersal fish species, with $95 \%$ confidence intervals (grey dashed and dotted lines with triangle).

rior mean and median of observation noise variances $\left(\tau^{2}\right)$ indicates that their posterior distributions were symmetric. However, for all the other remaining 13 fish species, due to the right skewed of their posterior distributions, the means were generally higher than the medians. 
Table 4. A summary of model selection information between Generalised Surplus Production Model (GSPM) and Classic Schaefer (logistic) Surplus Production Model (SSPM) based on predictive performance using Deviance Information Criterion (DIC) for fourteen studied demersal fish species.

\begin{tabular}{l|c|c}
\hline \multirow{2}{*}{ Species } & \multicolumn{2}{|c}{ Models } \\
\cline { 2 - 3 } & GSPM & SSPM \\
\cline { 2 - 3 } & Total DIC & Total DIC \\
\hline Elutheronema tetradactylum & 1.52 & 3.07 \\
\hline Lethrinus microdon & 10.48 & 12.38 \\
\hline Lutjanus johni & 22.33 & 25.59 \\
\hline Lutjanus malabaricus & 2.352 & 3.87 \\
\hline Otolithes ruber & 20.73 & 25.47 \\
\hline Pampus argenteus & 7.267 & 9.49 \\
\hline Parastromateus niger & 6.68 & 8.38 \\
\hline Platycephalus indicus & 11.24 & 13.14 \\
\hline Pomadasys kaakan & 7.14 & 8.96 \\
\hline Protonibea diacanthus & 2.65 & 6.16 \\
\hline Saurida tumbil & 11.82 & 13.92 \\
\hline Scomberoides commersonnianus & 8.68 & 10.98 \\
\hline Rhabdosargus sarba & 15.97 & 18.52 \\
\hline Trachinotus mookalee & 8.02 & 9.68 \\
\hline
\end{tabular}

\section{Estimates of reference points}

A summary of the results of fisheries management reference points derived from Bayesian state-space GSPM is graphically presented for all fourteen specified high-commercial demersal fish species through the stock status plots (i.e. Kobe plots or phase diagrams) in Figure 2; as well, time series of posterior median biomass with confidence intervals is shown in Figure 3.

The Kobe plot characterises, relative biomass $\left(B_{S}=B / B_{M S Y}\right)$ and relative fishing mortality rate $\left(F_{S}=F / F_{M S Y}\right)$ in a graph which provides four different quadrants, each indicating a different population status. The red region is kept for the worst case in which the stock is excessively overfished $\left(B / B_{M S Y}<1\right)$ and, at the same time, the overfishing is at a high rate $\left(F / F_{M S Y}>1\right)$. The green zone denotes a situation where no overfishing is happening $\left(F / F_{M S Y}<1\right)$ and where the stock is not overfished $\left(B / B_{M S Y}\right.$ $>1)$, so it is the best condition for the stock. The orange quadrant presents a situation where overfishing is occurring $\left(F / F_{M S Y}>1\right)$, while the stock is not overfished $\left(B / B_{M S Y}\right.$ $>1)$, so a decrease in fishing intensity would bring it back to the ideal green condition. The yellow subdivision shows that the stock has been overfished $\left(B / B_{M S Y}<1\right)$, while the overfishing has not occurred $\left(F / F_{M S Y}<1\right)$, so it will recover in due course if the fishing intensity is continued at the existing level.

According to Figure 2, the stock status of Greater lizardfish (Saurida tumbil), Javelin grunter (Pomadasys kaakan) and Tigertooth croaker (Otolithes ruber) are completely $(100 \%)$ in the red zone. Therefore, these stocks are being excessively overfished and are 
threatened with extinction. The other situation of fish species, despite being overfished in recent years, is in the yellow subdivision, which indicates that these stocks are not being overfished. So, they will recover in due course if the fishing intensity continues at the existing level. Amongst them, the recovery condition of Bartail flathead (Platycephalus indicus), Fourfinger threadfin (Elutheronema tetradactylum), Malabar blood snapper (Lutjanus malabaricus), Black pomfret (Parastromateus niger) and John's snapper (Lutjanus johni), is much better due to their high percentage in the yellow zone. Additionally, in terms of recovery condition, the Goldlined seabream (Rhabdosargus sarba), Smalltooth emperors (Lethrinus microdon), Talang queen fish (Scomberoides commersonnianus) and Blackspotted croaker (Protonibea diacanthus) because of their less percentage in the yellow zone are in the second place. Finally, the Silver pomfret (Pampus argenteus) with one percentage in the yellow zone has the worst recovery situation. It can be said that it is located in the red zone and is threatened with extinction. It is noteworthy that the overfishing and overfished results of the described demersal fish species in this research were similar to those previously described (Valinassab et al. 2010; Valinassab et al. 2003; Valinassab et al. 2006; Valinassab et al. 2005). These results about the overfishing and overfished demersal fish species are also similar to those by Osio et al. 2015 who expressed that $95 \%$ of the assessed and potentially $98 \%$ of the unassessed demersal fish are overexploited. Therefore, regarding the above-described conditions, the fish species extinction may be a possibility in the future.

Simulated biomass time series of the fourteen specified high-commercial demersal fish species with 95\% confidence intervals are considerable as shown in Figure 3.

According to the above-described results of the Kobe diagrams, in which all stocks are in critical condition and are threatened with extinction, the trend plots of simulated biomass confirm the previous results, due to the Biomass not having a good increasing trend. As the charts in Figure 3 show, the quantity of Biomass has not improved in recent years for all specified-fish species. If these trends unfortunately continue, the species may be extinct and the livelihoods of fishermen could be lost in the near future.

\section{Conclusion}

In summary, the Bayesian state-space GSPM under the MCMC algorithm was used to assess the stocks and provide fisheries management reference points for the fourteen high-commercial demersal fish species in the coastal domain of the study area. The authority of simulations about the models' parameters and fisheries management reference points were approved by common diagnostic convergence tests. All the assessed fish stocks encountered were overfished and being overfished. The assessment outcomes, which reveals that the stock statuses of all targeted fish species were deteriorating indicates that the available fishery management strategies of small-scale fishery in the study area were not enough and new strategies associated with sustainable management were necessary. 
As mentioned in the introduction, the scientific precise stock assessments have not been undertaken in Iran, especially on the southern coastal areas (such as the current study area) because of insufficient and limited information. Accordingly, it is one of the important reasons for the inefficiency of the available fishery management and conservation strategies for sustaining the studied fish species population status in the current study area. This reason is due to lack of applicable information for fisheries management and conservation planning (such as fisheries management reference points, biomass, harvest rate and stock status) that can be obtained from scientific precise stock assessments. Thus, in the short-term, the transferring of the obtained stock assessment outcomes of the current study to fisheries managers, planners and all other activists (such as fishermen) can improve the available fisheries strategies and harvesting treatments to rebuild and improve the current bad situation of studied fish species population status. Additionally, in the long run, the recommended use of the obtained stock assessment outcomes (e.g. management and biological reference points, biomass, harvest rate, stock status) for future research in line with appropriate ecosystem-based fishery management will determine the best strategies for preventing overfishing, improving, sustaining and conserving the above-overfished stocks. Hence, the obtained stock assessment outcomes in a viability theory framework to investigate various fishing scenarios for the implementation of the sustainable fishery management in the small-scale fishery sector of the current study area were used providing the details of the recommended viability theory modelling as an appropriate ecosystem-based fishery management approach in our further works.

\section{Acknowledgments}

The authors are grateful to Dr. Peter Sheldon Rankin from The University of Queensland, Australia, for his useful and constructive comments on estimating the abovementioned models. The authors thank the National Fishery Data Collection Unit of Iran Fisheries Organization, particularly Mr. Sabah Khorshidi Nergi, the head of National Fishery Data Collection Unit for providing the fishery data. The authors also acknowledge the Provincial Fisheries Department of Sistan and Baluchestan in Chabahar for providing complementary and description information about artisanal fishing vessels operating in the multispecies fishery of the study area and Offshore Fisheries Research Centre of Chabahar for its contribution in specifying fish species. Finally, the authors express their thanks to the anonymous reviewers for their comments that improved our manuscript.

\section{References}

Ando T (2010) Bayesian model selection and statistical modeling. CRC Press.

Arendt JD (1997) Adaptive intrinsic growth rates: An integration across taxa. The Quarterly Review of Biology 72(2): 149-177. https://doi.org/10.1086/419764 
Berkes F (2001) Managing small-scale fisheries: alternative directions and methods. IDRC.

Berliner LM (1996) Hierarchical Bayesian time series models. Maximum entropy and Bayesian methods. Springer, 15-22.

Bishop J (2006) Standardizing fishery-dependent catch and effort data in complex fisheries with technology change. Reviews in Fish Biology and Fisheries 16(1): 21-38. https://doi. org/10.1007/s11160-006-0004-9

Brodziak J, Ishimura G (2011) Development of Bayesian production models for assessing the North Pacific swordfish population. Fisheries Science 77(1): 23-34. https://doi. org/10.1007/s12562-010-0300-0

Buckland S, Newman K, Thomas L, Koesters N (2004) State-space models for the dynamics of wild animal populations. Ecological Modelling 171(1-2): 157-175. https://doi. org/10.1016/j.ecolmodel.2003.08.002

Chaloupka M, Balazs G (2007) Using Bayesian state-space modelling to assess the recovery and harvest potential of the Hawaiian green sea turtle stock. Ecological Modelling 205(1-2): 93-109. https://doi.org/10.1016/j.ecolmodel.2007.02.010

Chen Y, Chen L, Stergiou KI (2003) Impacts of data quantity on fisheries stock assessment. Aquatic Sciences 65(1): 92-98. https://doi.org/10.1007/s000270300008

Cheung WW, Sumaila UR (2015) Economic incentives and overfishing: A bioeconomic vulnerability index. Marine Ecology Progress Series 530: 223-232. https://doi.org/10.3354/meps11135

Clark JS, Gelfand AE (2006) Hierarchical modelling for the environmental sciences: statistical methods and applications. Oxford University Press on Demand.

Costello C, Ovando D, Hilborn R, Gaines SD, Deschenes O, Lester SE (2012) Status and solutions for the world's unassessed fisheries. Science 338(6106): 517-520. https://doi. org/10.1126/science.1223389

De Valpine P, Hastings A (2002) Fitting population models incorporating process noise and observation error. Ecological Monographs 72(1): 57-76. https://doi.org/10.1890/00129615(2002)072[0057:FPMIPN]2.0.CO;2

Fletcher R (1978) On the restructuring of the Pella-Tomlinson system. Fish Bulletin 76: 515-521.

Gelman A, Carlin JB, Stern HS, Rubin DB (2014) Bayesian data analysis. Chapman \& Hall/ CRC Boca Raton, FL, USA.

Gelman A, Meng X-L (2004) Applied Bayesian modeling and causal inference from incomplete-data perspectives. John Wiley \& Sons.

Geweke J (1991) Evaluating the accuracy of sampling-based approaches to the calculation of posterior moments. Federal Reserve Bank of Minneapolis, Research Department Minneapolis, MN, USA.

Gilks WR, Richardson S, Spiegelhalter DJ (1996) Introducing markov chain monte carlo. Markov chain Monte Carlo in practice 1: 19.

Haddon M (2010) Modelling and quantitative methods in fisheries. CRC press.

Harley SJ, Myers RA, Dunn A (2001) Is catch-per-unit-effort proportional to abundance? Canadian Journal of Fisheries and Aquatic Sciences 58(9): 1760-1772. https://doi. org/10.1139/f01-112

Heidelberger P, Welch PD (1983) Simulation run length control in the presence of an initial transient. Operations Research 31(6): 1109-1144. https://doi.org/10.1287/opre.31.6.1109 
Hilborn R, Walters CJ (1992) Quantitative fisheries stock assessment: Choice, dynamics and uncertainty. Reviews in Fish Biology and Fisheries 2(2): 177-178. https://doi.org/10.1007/ BF00042883

Jiao Y, Cortés E, Andrews K, Guo F (2011) Poor-data and data-poor species stock assessment using a Bayesian hierarchical approach. Ecological Applications 21(7): 2691-2708. https://doi.org/10.1890/10-0526.1

Jiao Y, Neves R, Jones J (2008) Models and model selection uncertainty in estimating growth rates of endangered freshwater mussel populations. Canadian Journal of Fisheries and Aquatic Sciences 65(11): 2389-2398. https://doi.org/10.1139/F08-141

Kéry M, Schaub M (2011) Bayesian population analysis using WinBUGS: a hierarchical perspective. Academic Press.

Kinas PG (1996) Bayesian fishery stock assessment and decision making using adaptive importance sampling. Canadian Journal of Fisheries and Aquatic Sciences 53(2): 414-423. https://doi.org/10.1139/f95-189

King R, Morgan B, Gimenez O, Brooks S (2009) Bayesian analysis for population ecology. CRC Press.

Kuparinen A, Mäntyniemi S, Hutchings JA, Kuikka S (2012) Increasing biological realism of fisheries stock assessment: Towards hierarchical Bayesian methods. Environmental Reviews 20(2): 135-151. https://doi.org/10.1139/a2012-006

Laloë F (1995) Should surplus production models be fishery description tools rather than biological models? Aquatic Living Resources 8(1): 1-16. https://doi.org/10.1051/ alr:1995001

Mäntyniemi SHP, Whitlock RE, Perälä TA, Blomstedt PA, Vanhatalo JP, Rincón MM, Kuparinen AK, Pulkkinen HP, Kuikka OS (2015) General state-space population dynamics model for Bayesian stock assessment. ICES Journal of Marine Science: Journal du Conseil 72(8): 2209-2222. https://doi.org/10.1093/icesjms/fsv117

Matthew S (2003) Small-scale fisheries perspectives on an ecosystem-based approach to fisheries management. Responsible Fisheries in the Marine Ecosystem, FAO, Rome: 47-64.

McAllister MK, Kirkwood G (1998) Using Bayesian decision analysis to help achieve a precautionary approach for managing developing fisheries. Canadian Journal of Fisheries and Aquatic Sciences 55(12): 2642-2661. https://doi.org/10.1139/f98-121

Meyer R, Millar RB (1999) BUGS in Bayesian stock assessments. Canadian Journal of Fisheries and Aquatic Sciences 56(6): 1078-1087. https://doi.org/10.1139/f99-043

Millar RB (2002) Reference priors for Bayesian fisheries models. Canadian Journal of Fisheries and Aquatic Sciences 59(9): 1492-1502. https://doi.org/10.1139/f02-108

Montenegro C, Branco M (2016) Bayesian state-space approach to biomass dynamic models with skewed and heavy-tailed error distributions. Fisheries Research 181: 48-62. https:// doi.org/10.1016/j.fishres.2016.03.021

Neiland AE, Béné C (2013) Poverty and small-scale fisheries in West Africa. Springer Science $\&$ Business Media.

Osio GC, Orio A, Millar CP (2015) Assessing the vulnerability of Mediterranean demersal stocks and predicting exploitation status of un-assessed stocks. Fisheries Research 171: 110-121. https://doi.org/10.1016/j.fishres.2015.02.005 
Pakzad HR, Pasandi M, Soleimani M, Kamali M (2014) Distribution and origin of heavy metals in the sand sediments in a sector of the Oman Sea (the Sistan and Baluchestan province, Iran). Quaternary International 345: 138-147. https://doi.org/10.1016/j. quaint.2014.03.031

Parent E, Rivot E (2012) Introduction to hierarchical Bayesian modeling for ecological data. CRC Press.

Pauly D (2006) Major trends in small-scale marine fisheries, with emphasis on developing countries, and some implications for the social sciences. Maritime Studies 4: 7-22.

Pella JJ, Tomlinson PK (1969) A generalized stock production model. Inter-American Tropical Tuna Commission.

Plummer M, Best N, Cowles K, Vines K (2006) CODA: Convergence diagnosis and output analysis for MCMC. R News 6: 7-11.

Punt AE, Hilborn RAY (1997) Fisheries stock assessment and decision analysis: The Bayesian approach. Reviews in Fish Biology and Fisheries 7(1): 35-63. https://doi. org/10.1023/A:1018419207494

Punt AE, Smith DC, Smith ADM (2011) Among-stock comparisons for improving stock assessments of data-poor stocks: The "Robin Hood" approach. ICES Journal of Marine Science: Journal du Conseil 68(5): 972-981. https://doi.org/10.1093/icesjms/fsr039

Punt AE, Szuwalski C (2012) How well can F MSY and B MSY be estimated using empirical measures of surplus production? Fisheries Research 134: 113-124. https://doi. org/10.1016/j.fishres.2012.08.014

Quinn TJ, Deriso RB (1999) Quantitative fish dynamics. Oxford University Press.

Rankin PS, Lemos RT (2015) An alternative surplus production model. Ecological Modelling 313: 109-126. https://doi.org/10.1016/j.ecolmodel.2015.06.024

Salas S, Chuenpagdee R, Seijo JC, Charles A (2007) Challenges in the assessment and management of small-scale fisheries in Latin America and the Caribbean. Fisheries Research 87(1): 5-16. https://doi.org/10.1016/j.fishres.2007.06.015

Schaefer MB (1957) A study of the dynamics of the fishery for yellowfin tuna in the eastern tropical Pacific Ocean. Inter-American Tropical Tuna Commission.

Seaman JW III, Seaman Jr JW, Stamey JD (2012) Hidden Dangers of Specifying Noninformative Priors. The American Statistician 66(2): 77-84. https://doi.org/10.1080/00031305.2 012.695938

Spiegelhalter DJ, Best NG, Carlin BP, Van Der Linde A (2002) Bayesian measures of model complexity and fit. Journal of the Royal Statistical Society. Series B, Statistical Methodology 64(4): 583-639. https://doi.org/10.1111/1467-9868.00353

Sturtz S, Ligges U, Gelman A (2010) R2OpenBUGS: a package for running OpenBUGS from R. http://wwwcranrprojectorg/web/packages/R2OpenBUGS/vignettes/R2OpenBUGSpdf Thomas A, O’Hara B, Ligges U, Sturtz S (2006) Making BUGS open. R News 6: 12-17.

Valinassab T, Adjeer M, Momeni M (2010) Biomass estimation of demersal fishes in the Persian Gulf and Oman Sea by swept area method. Final Report. Iranian Fisheries Research Organization Press, Tehran.

Valinassab T, Daryanabard R, Dehghani R (2003) Monitoring of demersal resources by swept area method in the Oman Sea waters. Final Report. Tehran, Iran 
Valinassab T, Daryanabard R, Dehghani R, Pierce GJ (2006) Abundance of demersal fish resources in the Persian Gulf and Oman Sea. Journal of the Marine Biological Association of the United Kingdom 86(06): 1455-1462. https://doi.org/10.1017/S0025315406014512

Valinassab T, Dehghani R, Khorshidian K (2005) Biomass estimation of demersal resources in the Persian Gulf and Gulf of Oman by swept area method. Final Report Iranian Fisheries Research Organization (IFRO), Tehran, $121 \mathrm{pp}$.

Wikle CK, Berliner LM, Cressie N (1998) Hierarchical Bayesian space-time models. Environmental and Ecological Statistics 5(2): 117-154. https://doi.org/10.1023/A:1009662704779

Xiao Y (1998) Two simple approaches to use of production models in fish stock assessment. Fisheries Research 34(1): 77-86. https://doi.org/10.1016/S0165-7836(97)00064-7

Ye Y, Dennis D (2009) How reliable are the abundance indices derived from commercial catch-effort standardization? Canadian Journal of Fisheries and Aquatic Sciences 66(7): 1169-1178. https:// doi.org/10.1139/F09-070

Yu H, Jiao Y, Carstensen LW (2013) Performance comparison between spatial interpolation and GLM/GAM in estimating relative abundance indices through a simulation study. Fisheries Research 147: 186-195. https://doi.org/10.1016/j.fishres.2013.06.002

Zhu X, Day AC, Carmichael TJ, Tallman RF (2014) Hierarchical Bayesian Modeling for Cambridge Bay Arctic Char, Salvelinus Alpinus (L.), Incorporated with Precautionary Reference Points.

\section{Appendix I}

Procedure of prior distributions functions used for parameters of all Bayesian statespace GSPM

Log-normal distribution procedure for intrinsic growth rate $(r)$

Standard Deviation $=\mathrm{x}$

Average of Intrinsic Growth Rate $(\mathrm{r})=\mathrm{y}$

Precision of Prior $=1 / \log \left(1+x^{\wedge} 2\right)$

Average of Prior $=\log (y)-(0.5 /$ Precision of Prior $)$

$\mathrm{r} \sim$ dlnorm (Average of prior, Precision of prior)

Inverse Gamma Distribution Procedure for the Process and Observation Noise Variances

Shape Parameter $=\mathrm{x}$

Scale Parameter $=y$

Gamma dgamma $(x, y)$

Inverse-Gamma = 1/Gamma

Log-Normal Distribution Procedure for Initial Relative Biomass P[1]

B0=the Biomass in First Time

$\mathrm{Kmin}=$ minimum carrying capacity is considered equal to minimum Historical catches.

Kmax $=$ maximum carrying capacity is considered equal to ten times the minimum

Historical catches.

$\mathrm{Pi} \sim \operatorname{dunif}(\mathrm{B} 0 / \mathrm{Kmax}, \mathrm{B} 0 / \mathrm{Kmin})$ 
isigma $=$ Inverse Gamma Distribution for process noise variances

$\operatorname{Pm}[1]<-\log (\mathrm{Pi})$

$\mathrm{P}[1] \sim \operatorname{dlnorm}(\mathrm{Pm}[1]$, isigma $)$

\section{Appendix 2}

Trace plots for Bayesian state-space GSPM parameters (r, K, q, z, (sigma), and (tau)) for fourteen studied demersal fish species. Consider figures A1-14.
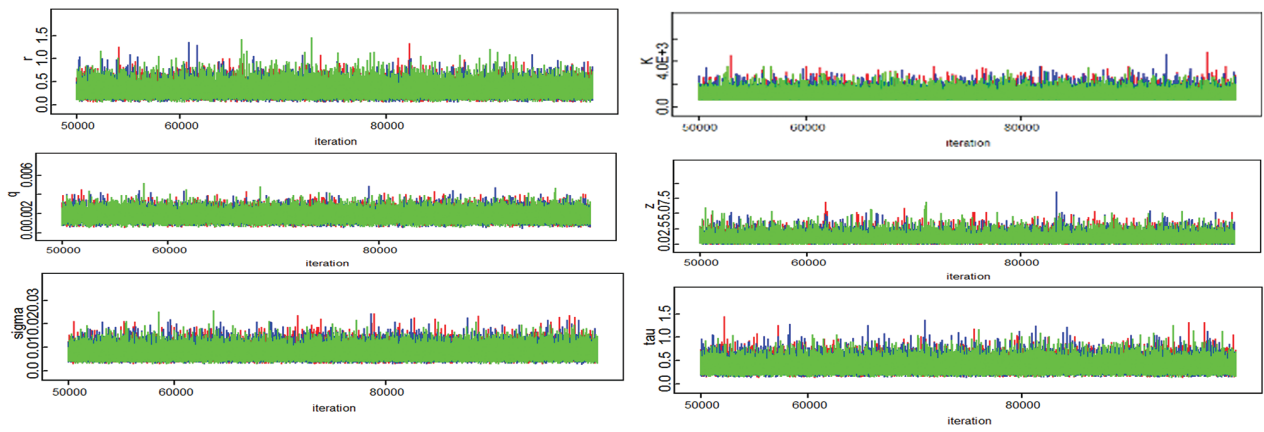

Figure AI. Trace plots for Bayesian state-space GSPM parameters of Elutheronema tetradactylum model.
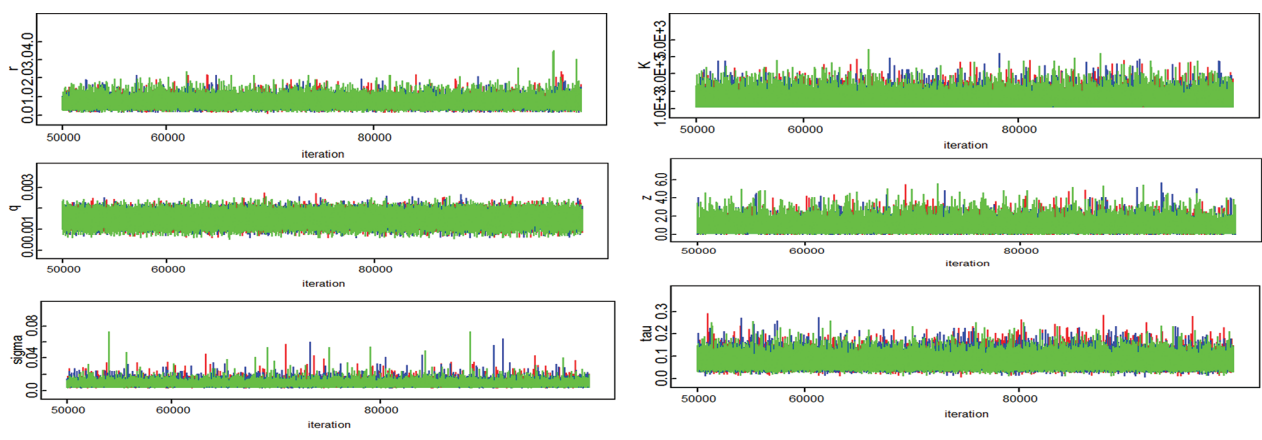

Figure A2. Trace plots for Bayesian state-space GSPM parameters of Lethrinus microdon model. 

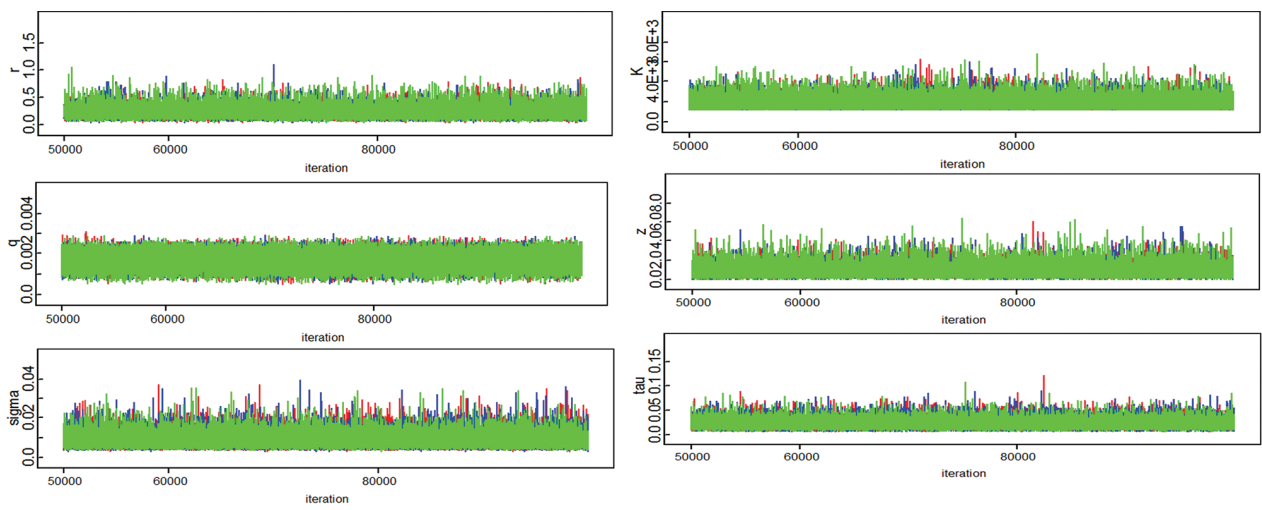

Figure A3. Trace plots for Bayesian state-space GSPM parameters of Lutjanus johni model.
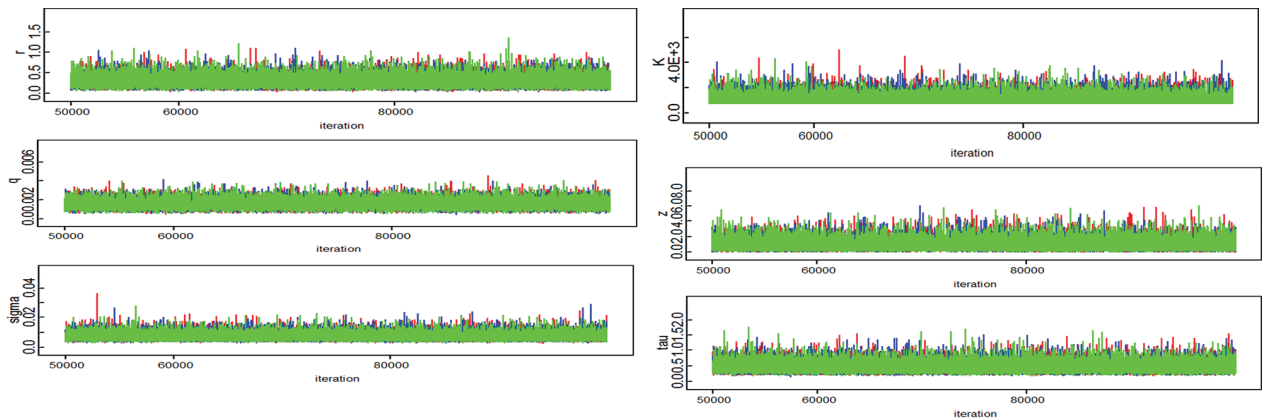

Figure A4. Trace plots for Bayesian state-space GSPM parameters of Lutjanus malabaricus model.
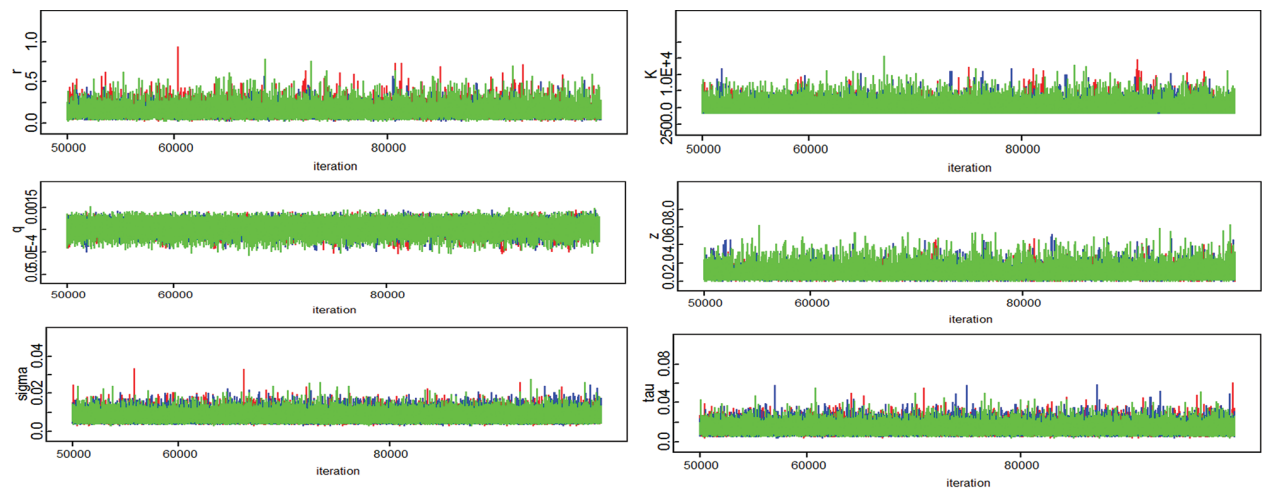

Figure A5. Trace plots for Bayesian state-space GSPM parameters of Otolithes ruber model. 

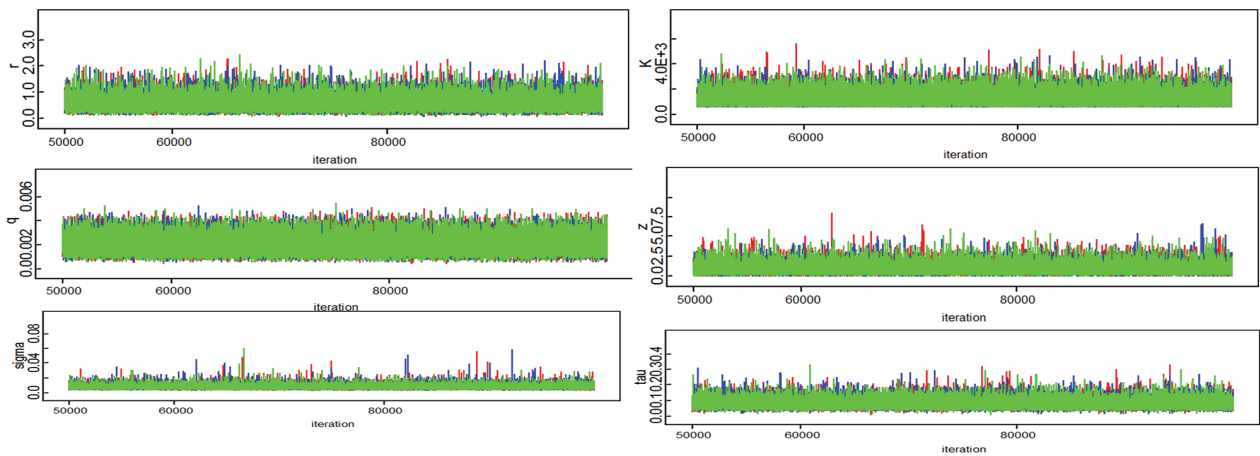

Figure A6. Trace plots for Bayesian state-space GSPM parameters of Pampus argenteus model.
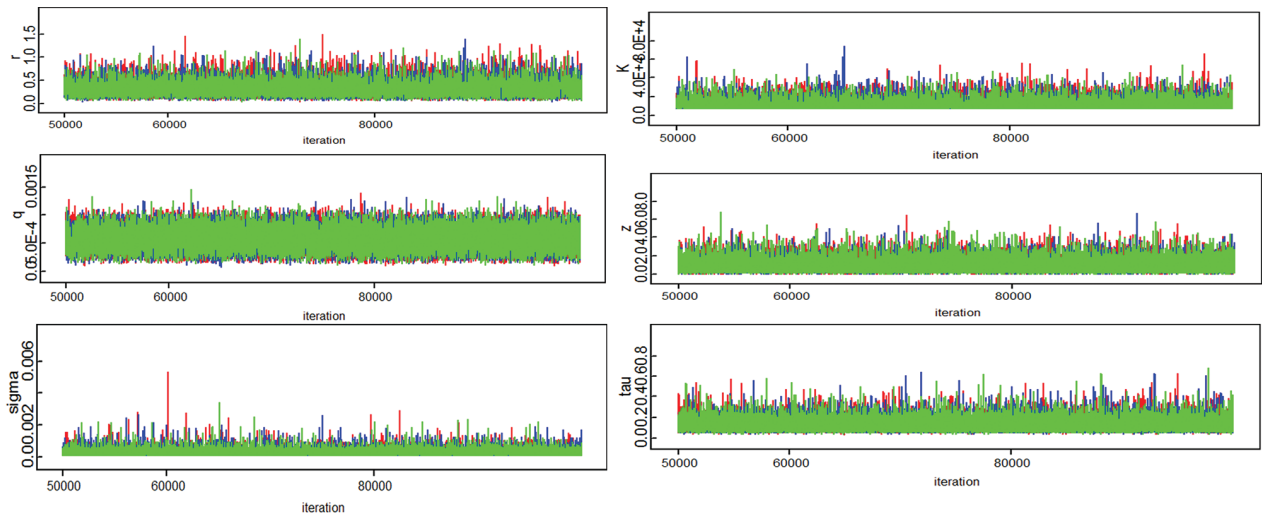

Figure A7. Trace plots for Bayesian state-space GSPM parameters of Parastromateus niger model.
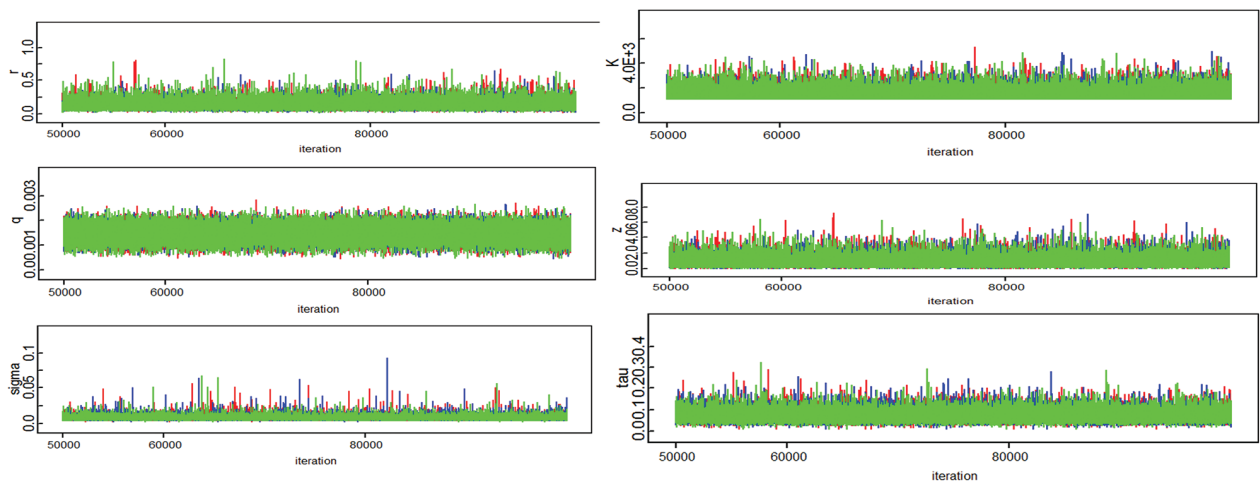

Figure A8. Trace plots for Bayesian state-space GSPM parameters of Platycephalus indicus model. 

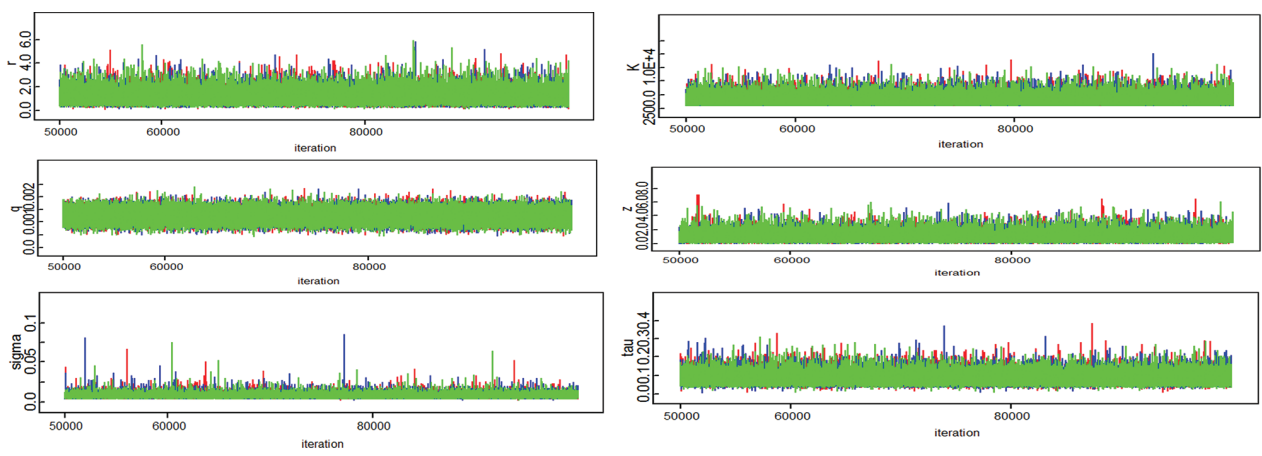

Figure A9. Trace plots for Bayesian state-space GSPM parameters of Pomadasys kaakan model.
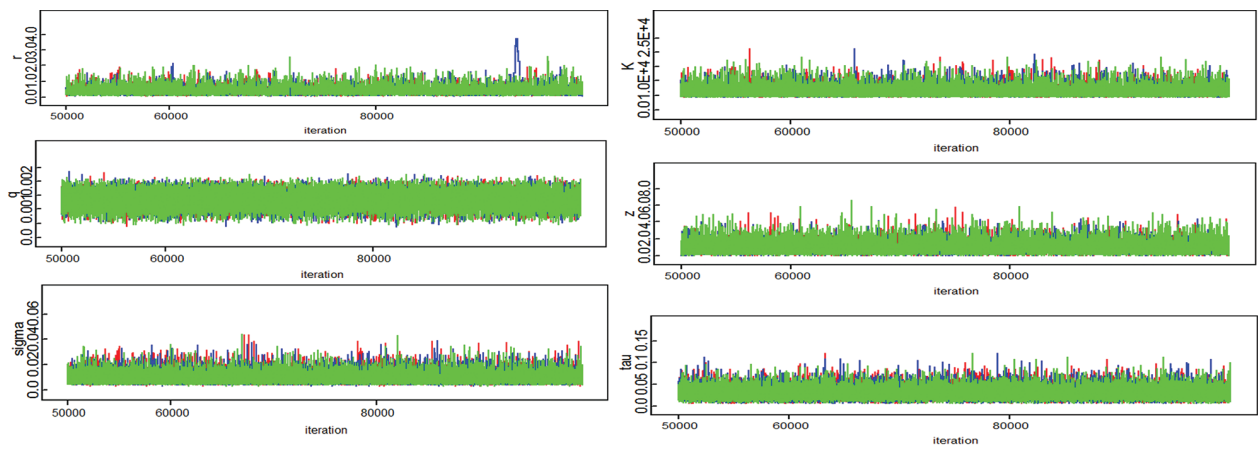

Figure A 1 0. Trace plots for Bayesian state-space GSPM parameters of Protonibea diacanthus model.
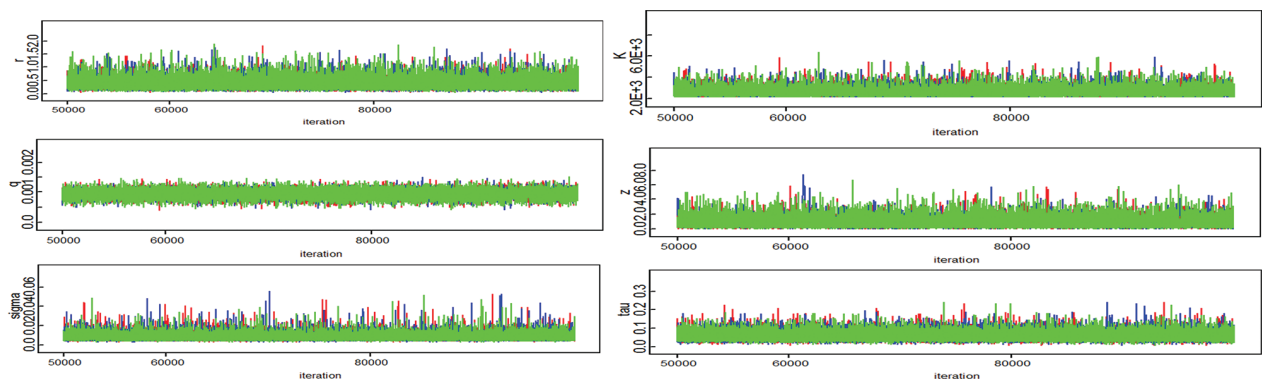

Figure AI I. Trace plots for Bayesian state-space GSPM parameters of Saurida tumbil model. 

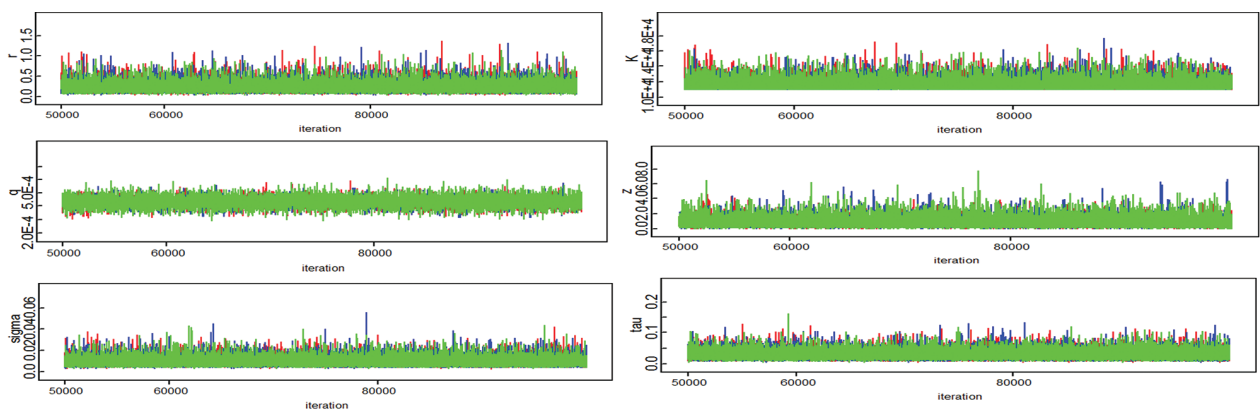

Figure A 12. Trace plots for Bayesian state-space GSPM parameters of Scomberoides commersonnianus model.
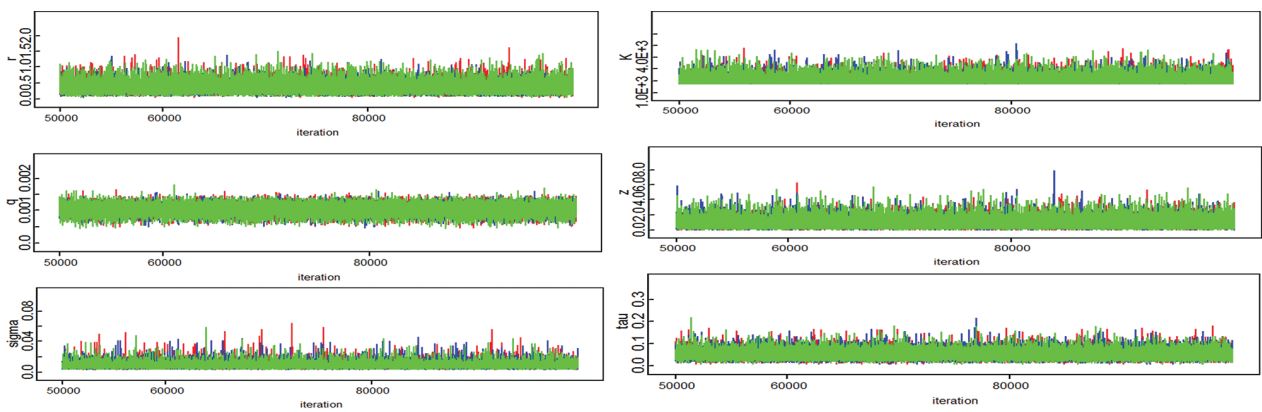

Figure A 13. Trace plots for Bayesian state-space GSPM parameters of Rhabdosargus sarba model.
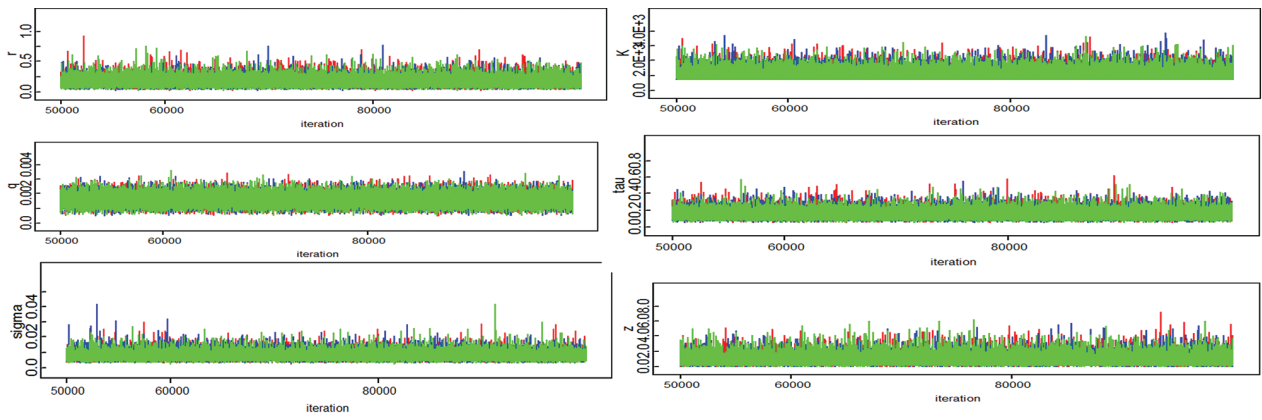

Figure A I 4. Trace plots for Bayesian state-space GSPM parameters of Trachinotus mookalee model. 